هجِلة الفنون والندب وعاوم اللإنسانيات واللاجِمهاع

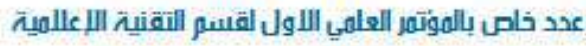

كلية التقنية اللدازية -جاهعت السليهانية التقنية

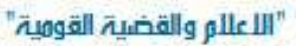

www.jalhss.com ISSN online: 2414-3383 ISSN print $2616-3810$

2019 gll (38) (3)

\title{
Kurdish Issue in the International Electronic Newspapers
}

\author{
Assistant lecture \\ Mahdy Abdwlah \\ Department of Technical media \\ College of Technical administrators \\ Sulaimani Polytechnic University \\ Iraq
}

\begin{abstract}
This research centers around the subject of National Identity in the international electronic magazines. It is an investigation for deeper understanding of national identity because nowadays this subject is a wide field for the negotiation of the social science researches. In my opinion Kurds nowadays are seeking and searching for their national identity more than anytime. Media in general especially electronic media has a crucial role and influence in improving this subject.

This research demonstrates the importance and need for the existence of national identity as it's requested and inquired by a community's individuals. Despite of the obstacles which encourage building national identity even more. The research starts theoretically. The beginning is about those who stand against having national and individual identity. Then the term of identity and how one can comprehend social identity as an influential and theoretical aspect are analyzed. Finally, a comparison between both aspects will be discussed.
\end{abstract}




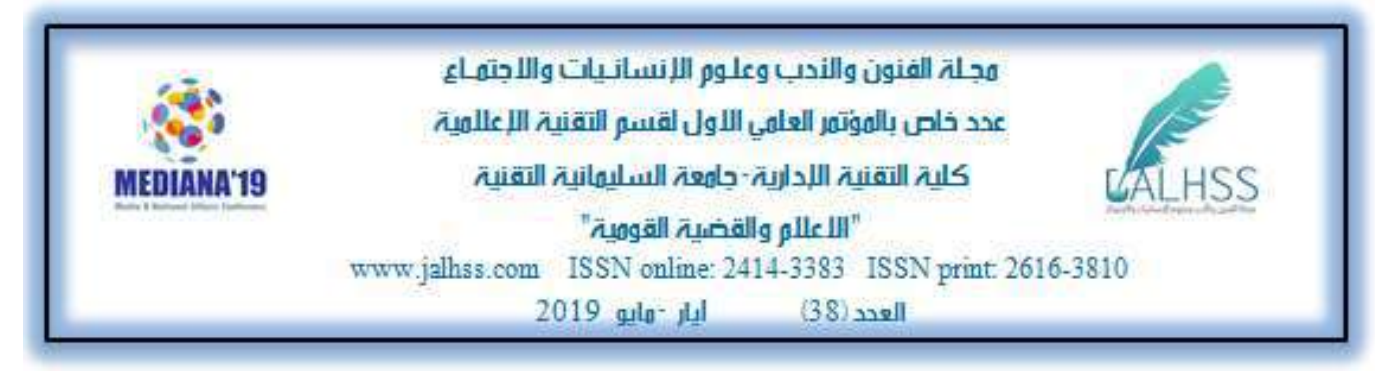

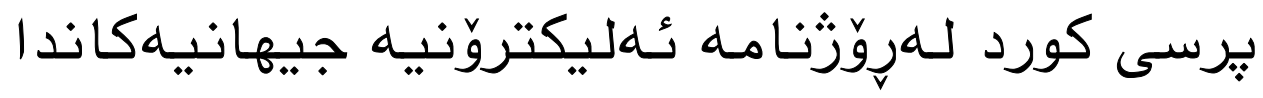

$$
\begin{aligned}
& \text { مهدي عبدالله }
\end{aligned}
$$

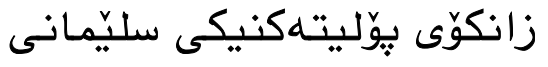

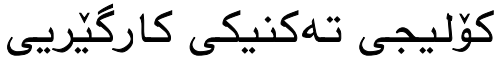

$$
\begin{aligned}
& \text { بـهى تهكنيكى ميديا }
\end{aligned}
$$

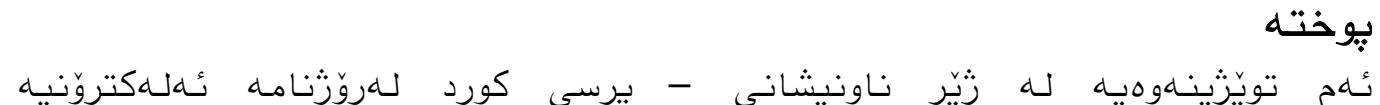

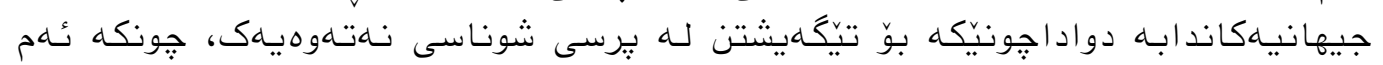

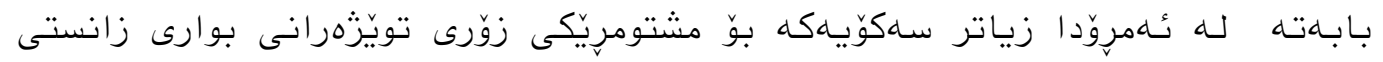

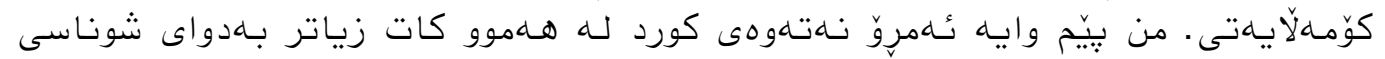

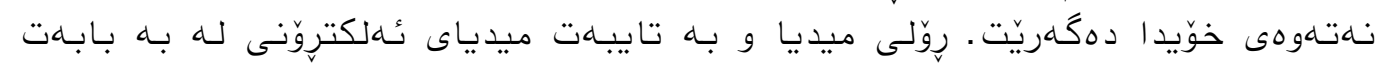

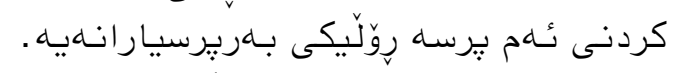

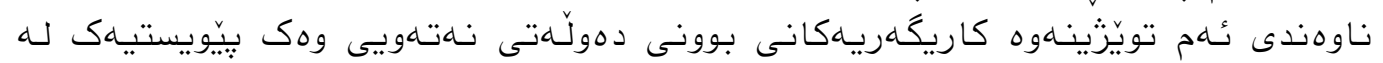

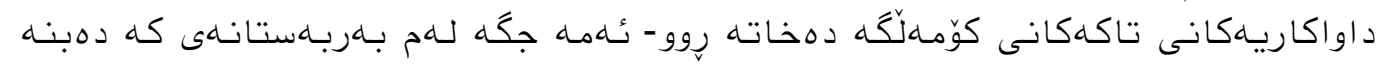

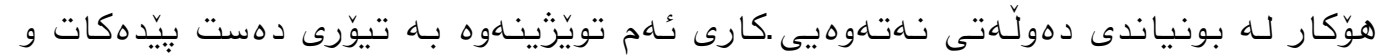

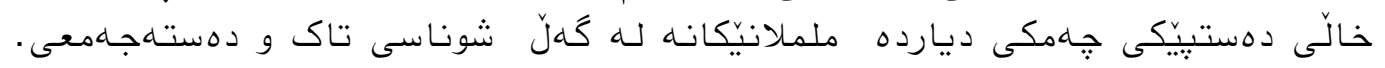

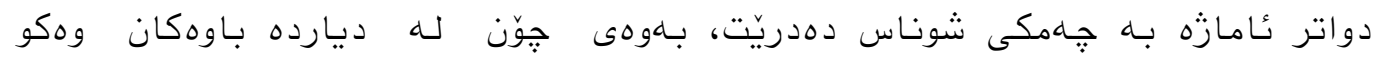

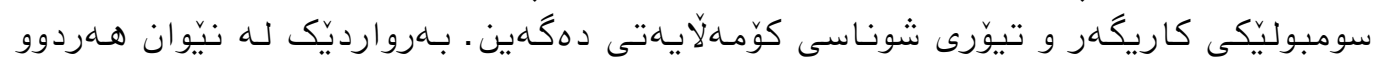
دياردهكان دهكريّيت. 

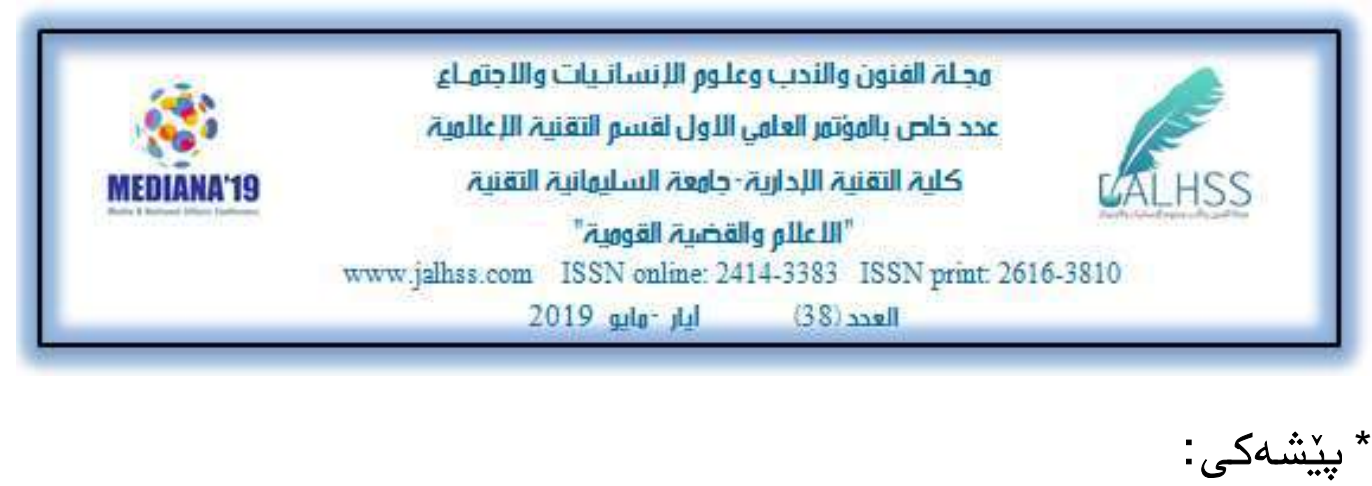

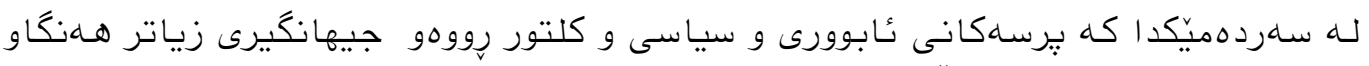

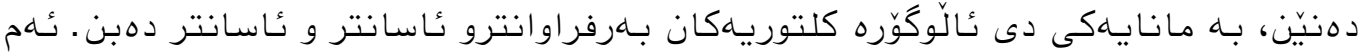

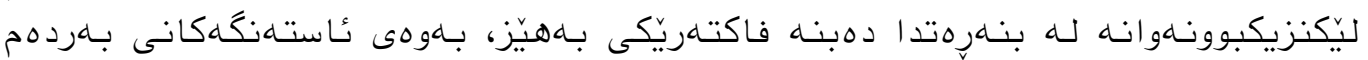

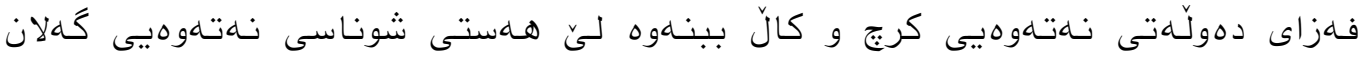

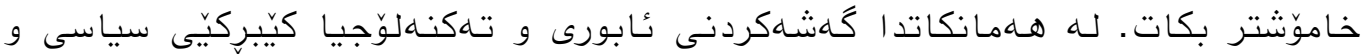

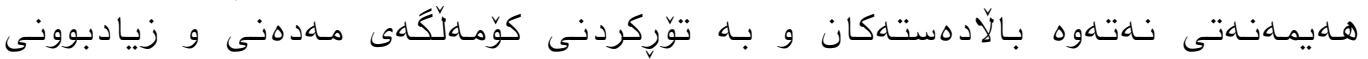

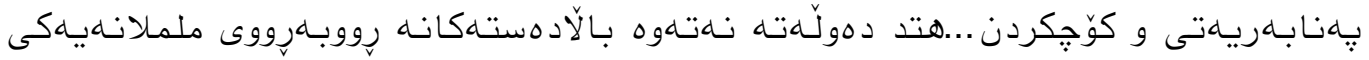
قولّ دهكاتحهوه.

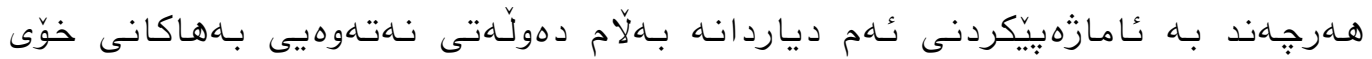

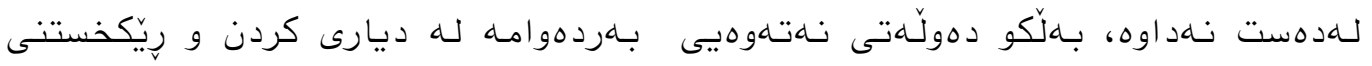

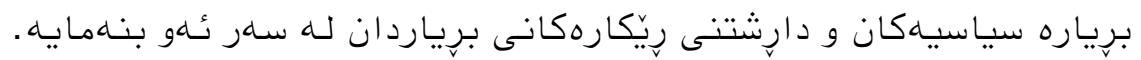

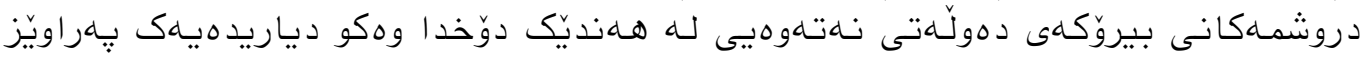

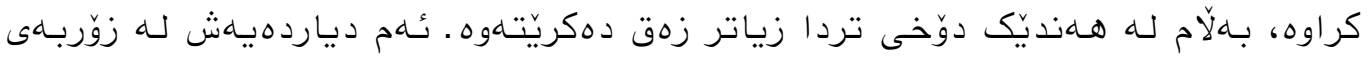

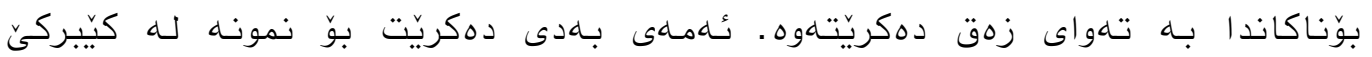

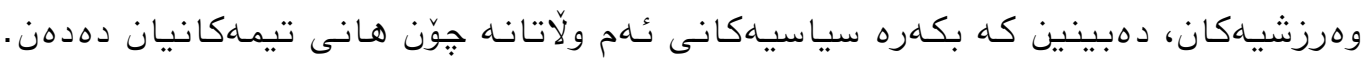

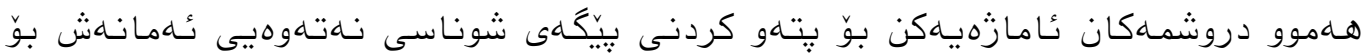

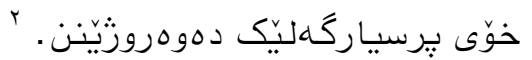

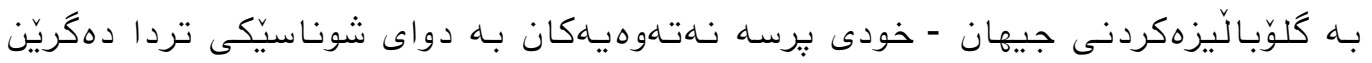

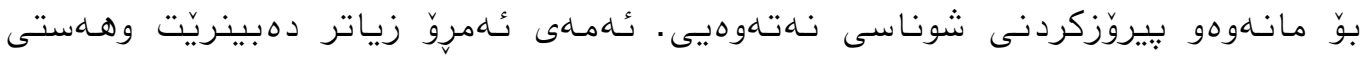

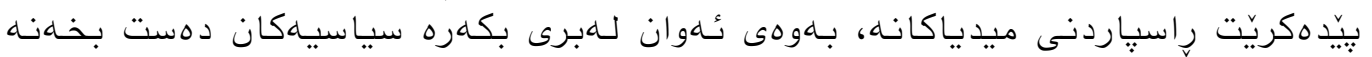

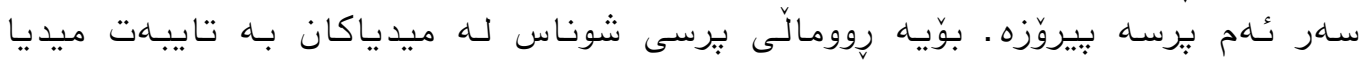

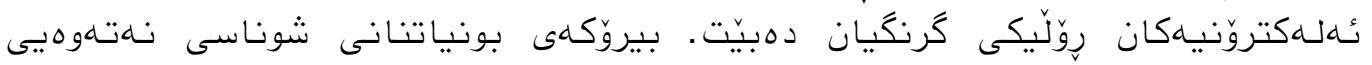

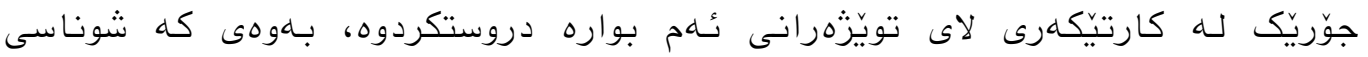

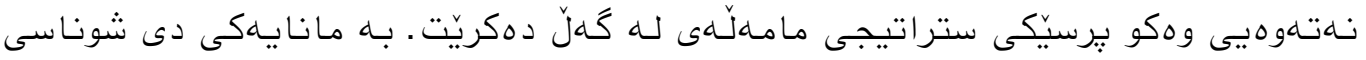

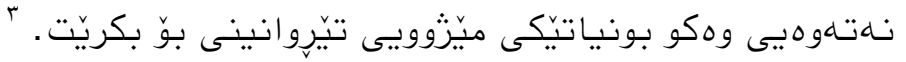

${ }^{1}$ Sander Cvetkovic. Sprachpolitik und nationale Identität im Sozialistischen Jugoslawien 2011 S. 20Instituts an der Freien Universität Berlin.

${ }^{2}$ Sander Cvetkovic. Sprachpolitik und nationale Identität im Sozialistischen Jugoslawien 2011 S. 28 Instituts an der Freien Universität Berlin.

${ }^{3}$ Frank Marcinkowski, Barbara Pfetsch. Nationale Identitätals Medieninhalt, Nomos Verlagsgesellschaft, Baden-Baden 2014. S. 17 


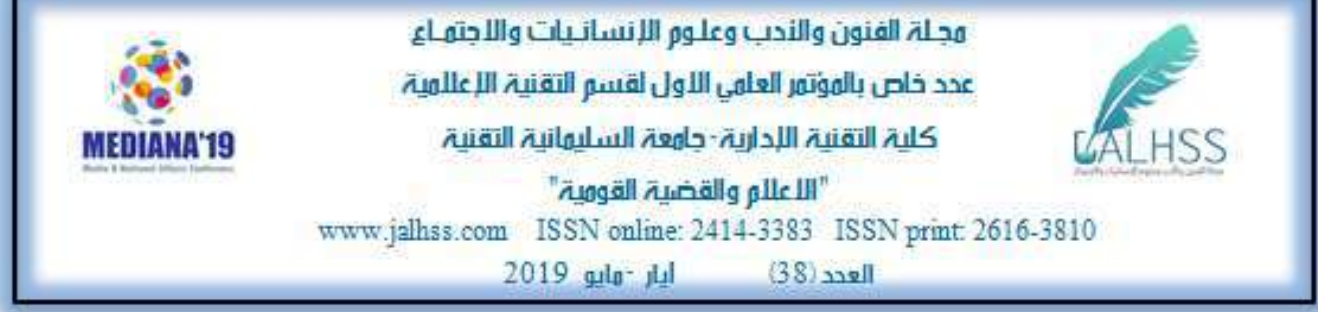

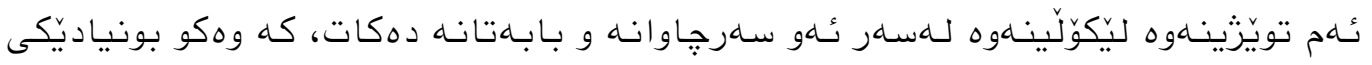

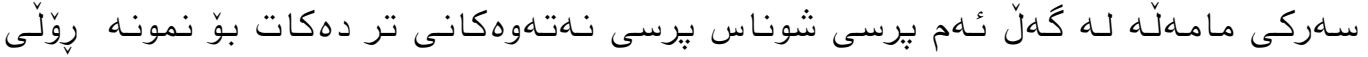

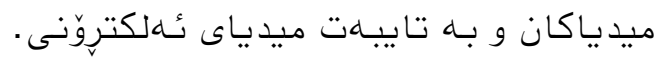

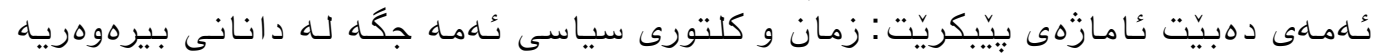

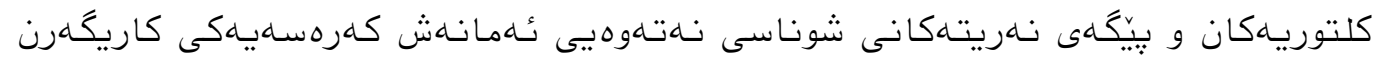

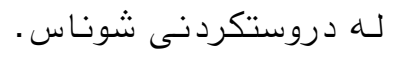

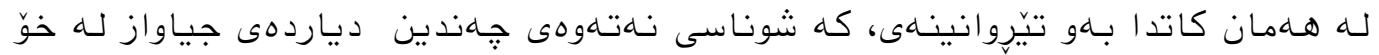

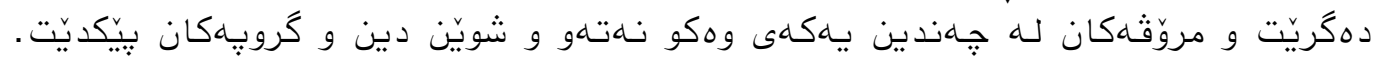

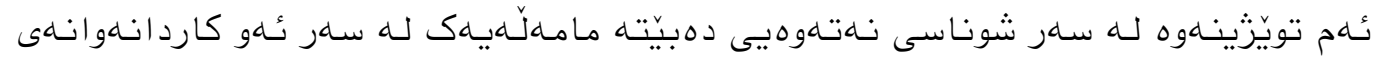

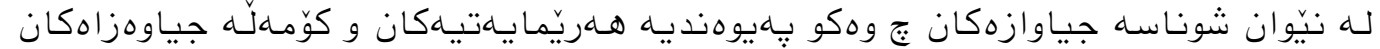

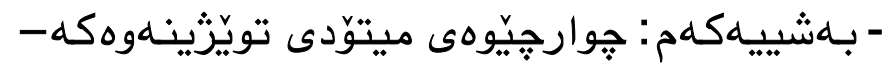

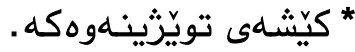

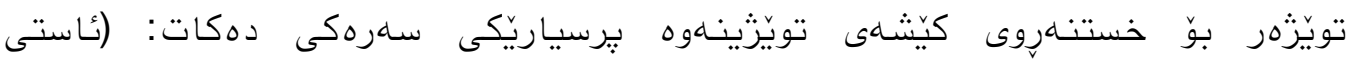

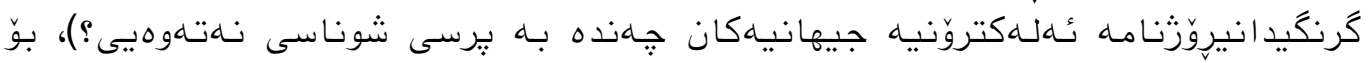

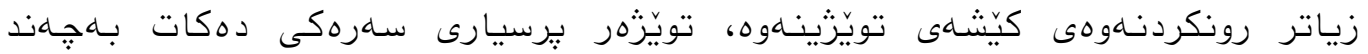

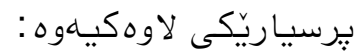

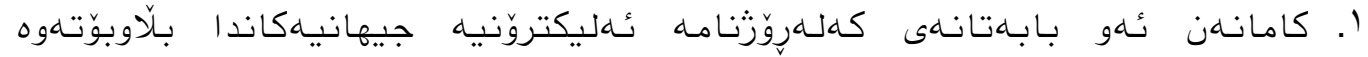

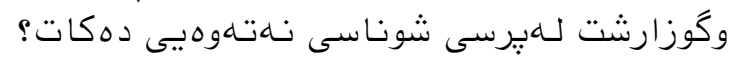

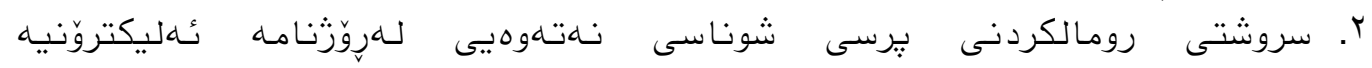
جيهانيه كاندا.

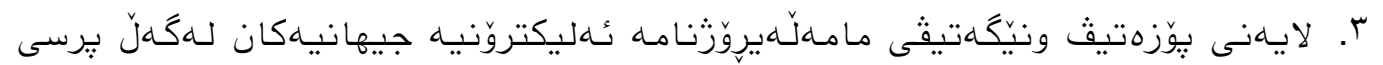

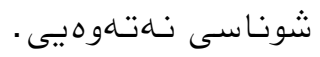

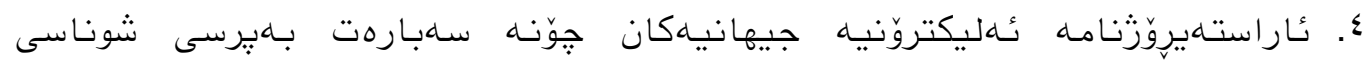

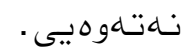

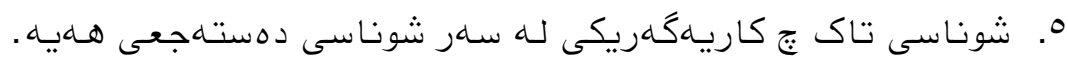

${ }^{4}$ C. Leggewie u.a.: Der Kampf um die europäische Erinnerung - München 2011: C.H. Beck Verlag S. 121. 


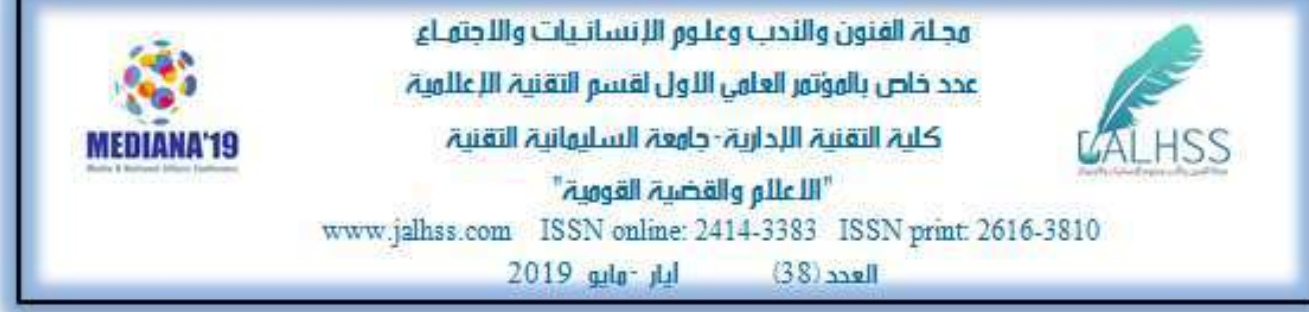

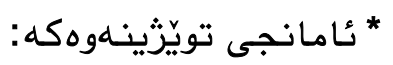

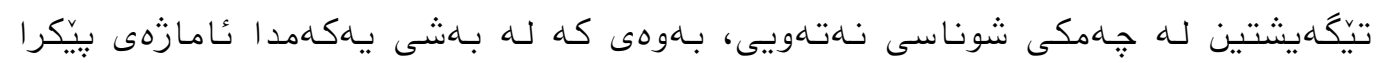

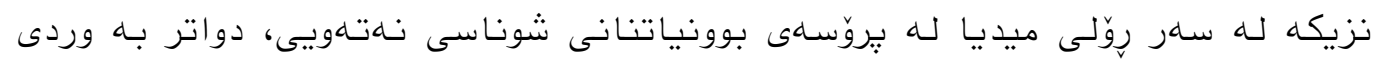

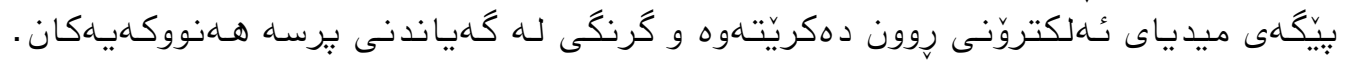

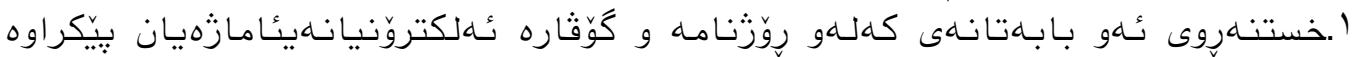

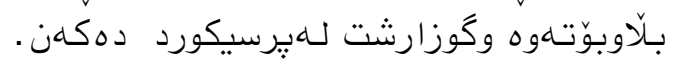

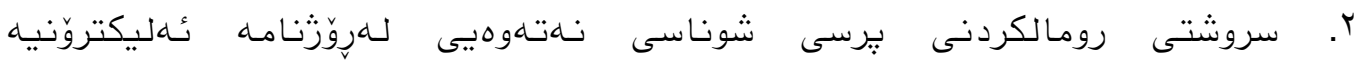
جيهانيهكاندا.

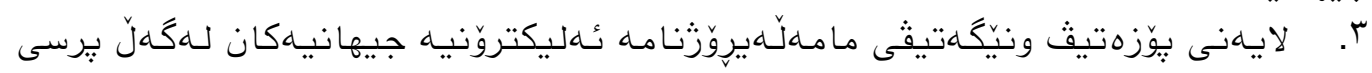

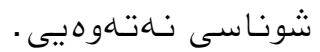

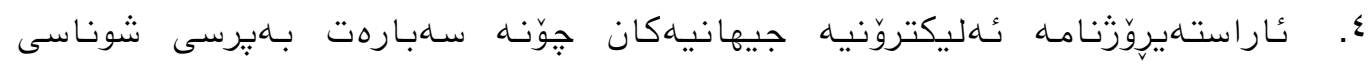
نـالتهوهيى.

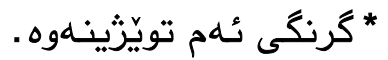

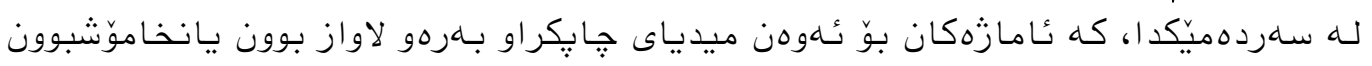

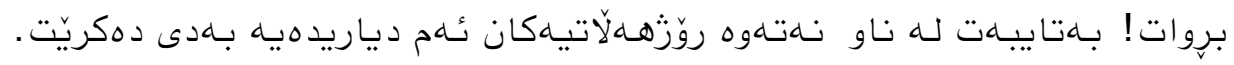

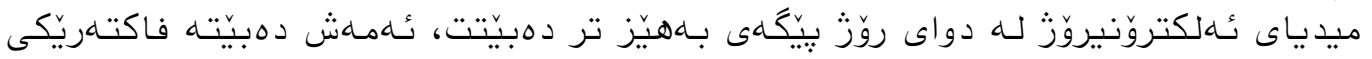

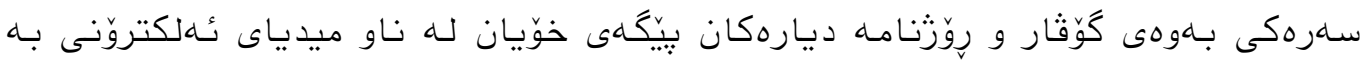

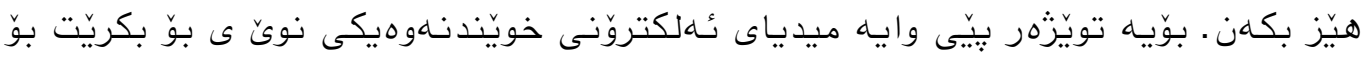

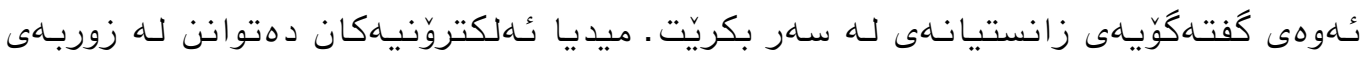

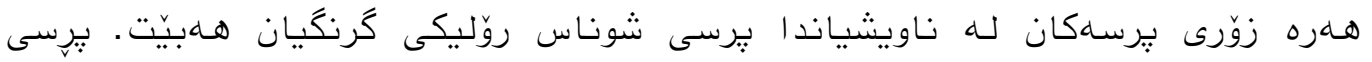

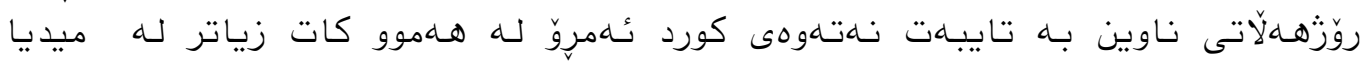

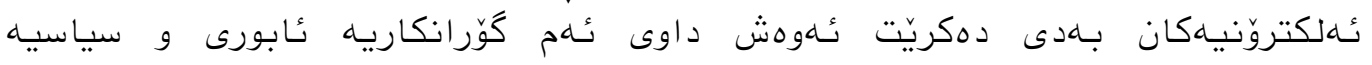

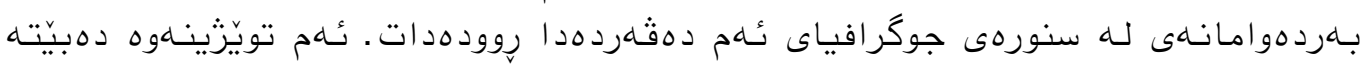

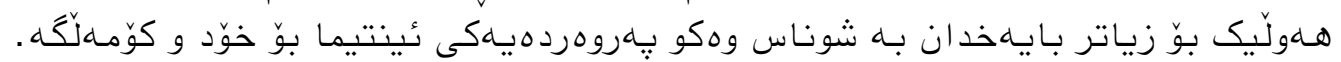

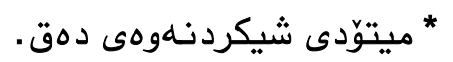

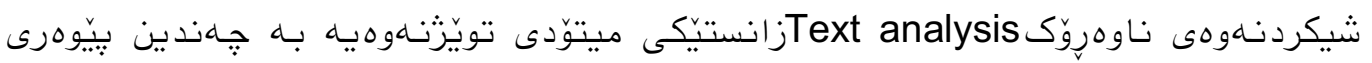

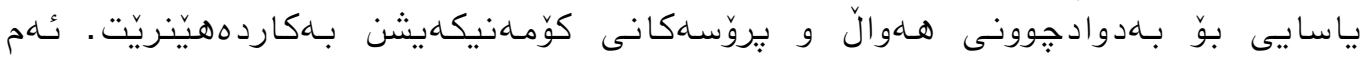

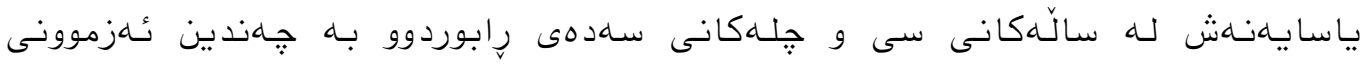




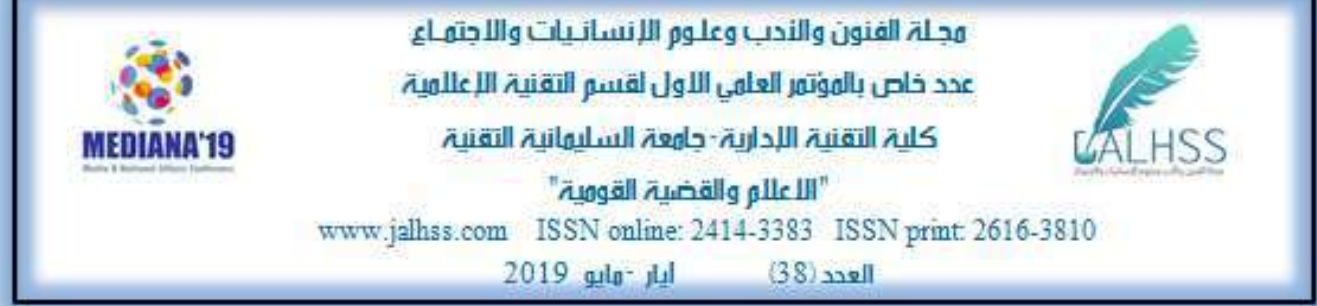

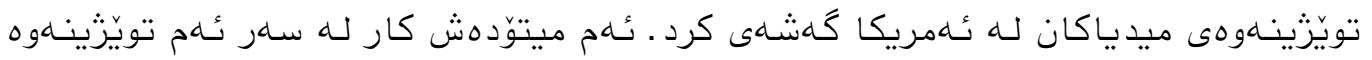

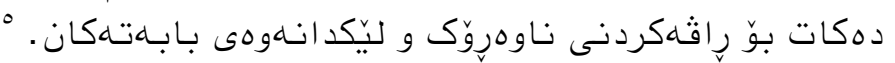

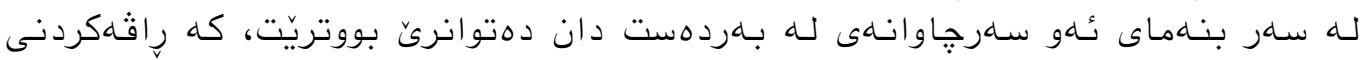

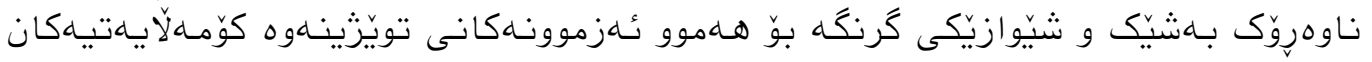

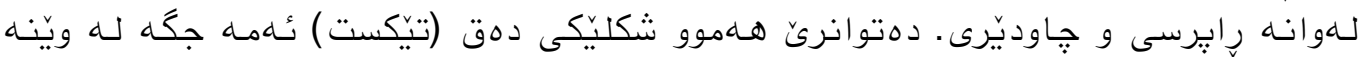

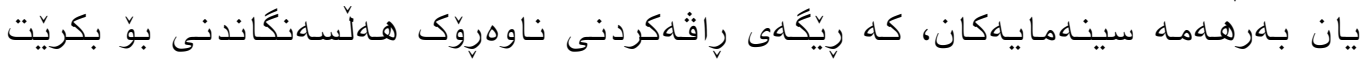

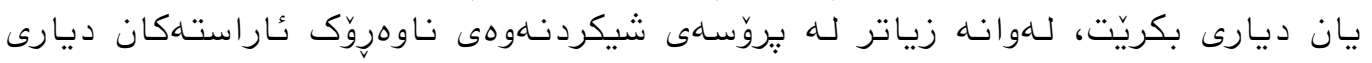

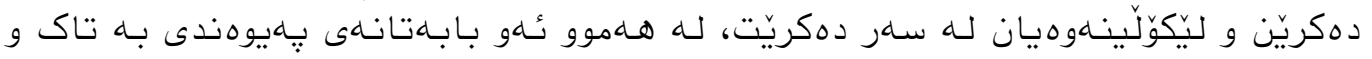

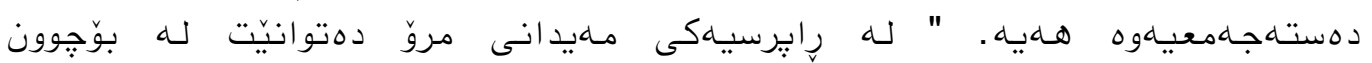

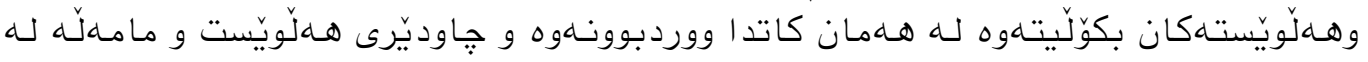

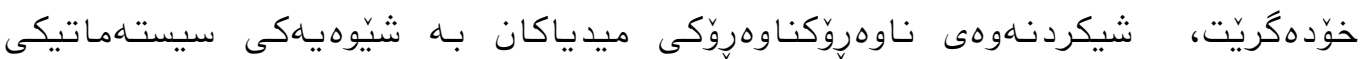

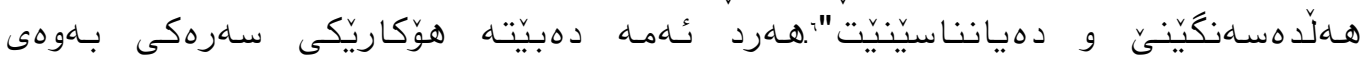

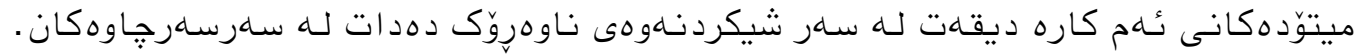

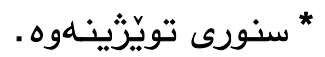

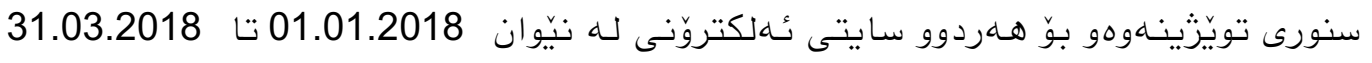

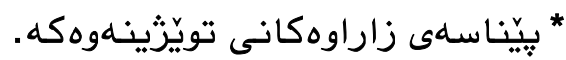

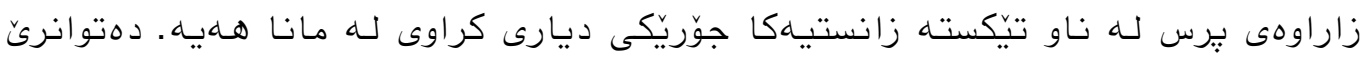

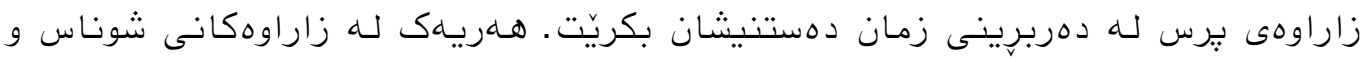

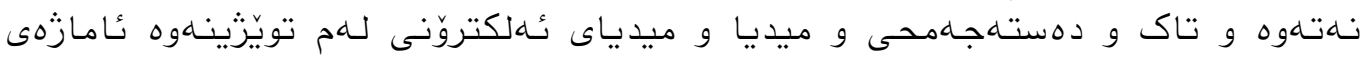

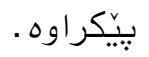

${ }^{5}$ Atteslander Peter, Methoden der empirischen Sozialforschung, Berlin, New York: Walter de Cruyter $\mathrm{GmbH}$ 10. neu überarbeitete und erweiterte Auflage 2003.

${ }^{6}$ Meier Klaus. Journalistik, Konstanz: UVK Verlagsgesellschaft, 2007. S 47 


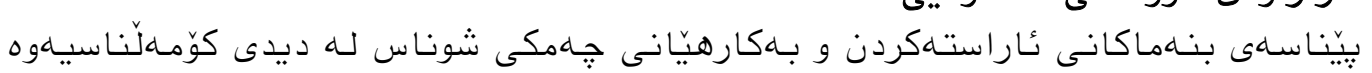

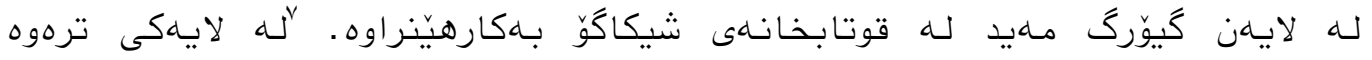

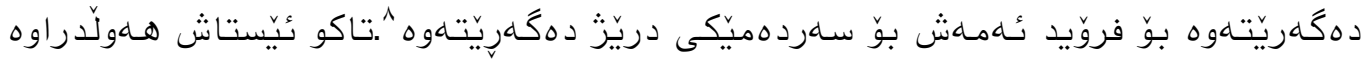

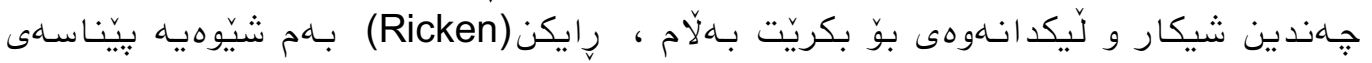

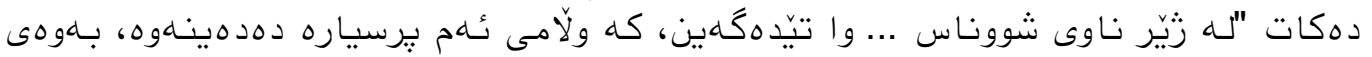

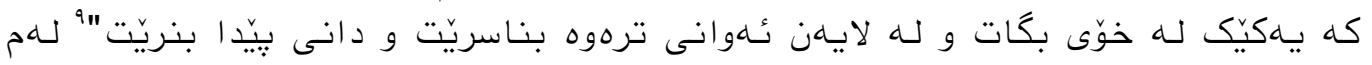

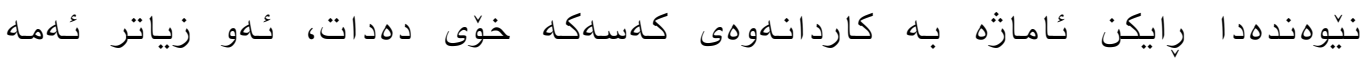

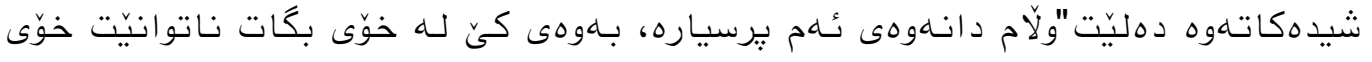

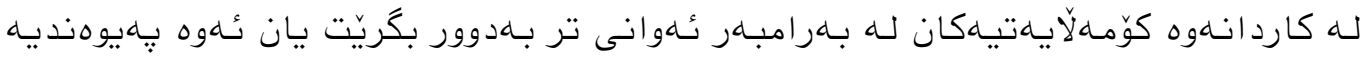

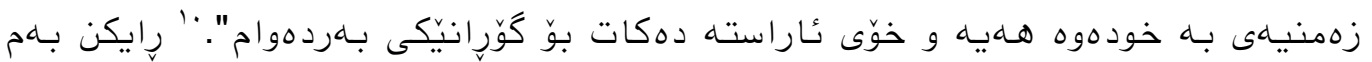

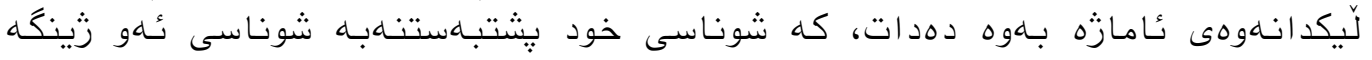

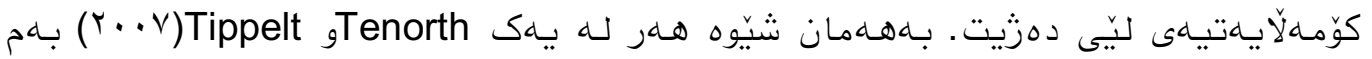

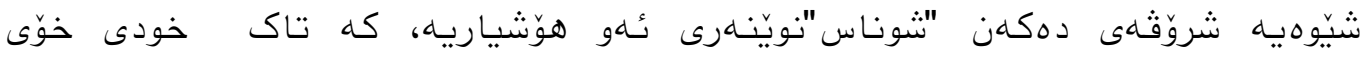

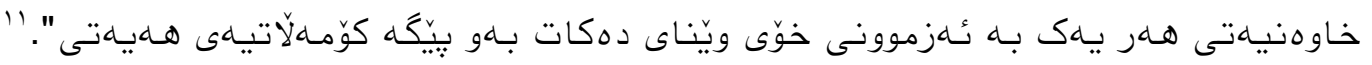

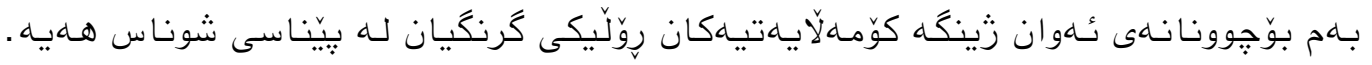

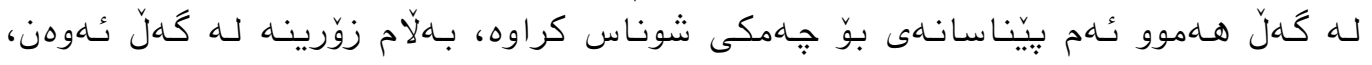

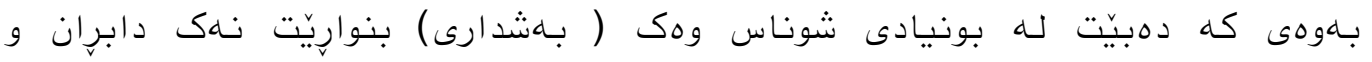

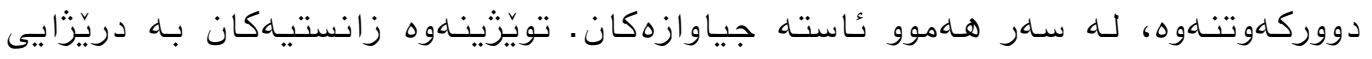

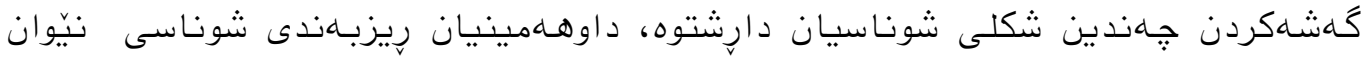

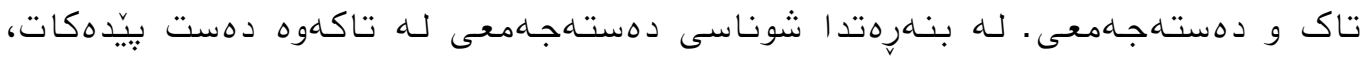

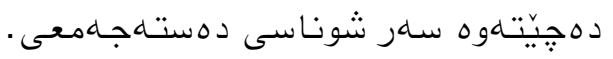

${ }^{7}$ https://www.owep.de/artikel/634/identitaet-konstruktion-und-soziale-tatsache. 20.03 .2018

${ }^{8}$ Norbert Ricken: Anerkennung als pädagogisches Problem. Markierungen im erziehungswissenschaftlichen Diskurs. 2010. S. 45 Universität Buchum

${ }^{9}$ Norbert Ricken: Anerkennung als pädagogisches Problem. Markierungen im erziehungswissenschaftlichen Diskurs. 2010. S. 65 Universität Buchum

${ }^{10}$ Norbert Ricken. 70

${ }^{11}$ Tenorth / Tippelt (Hrsg.) Lexikon Pädagogik 2007 S. 150 


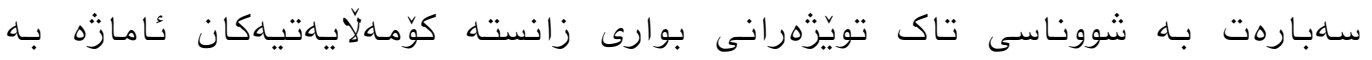

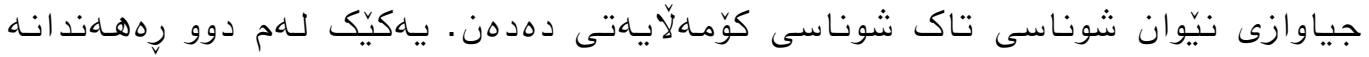

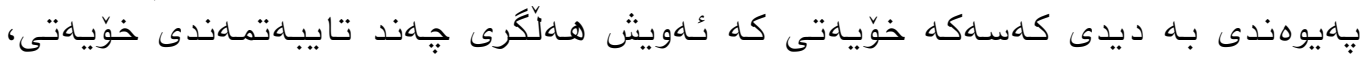

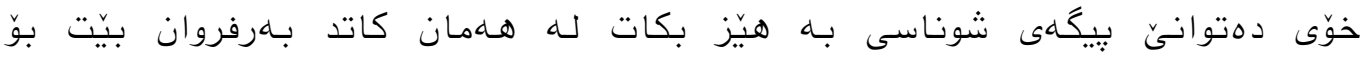

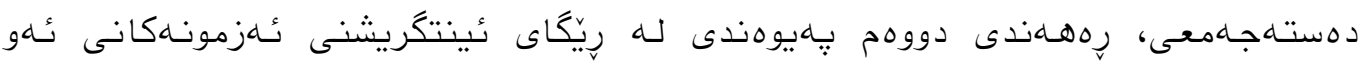

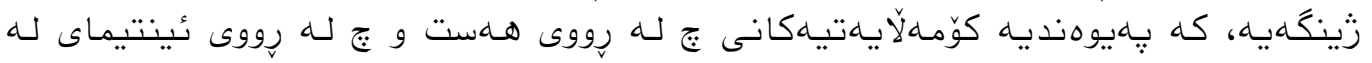

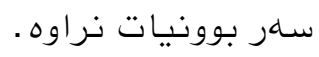

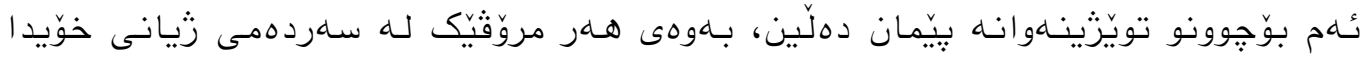

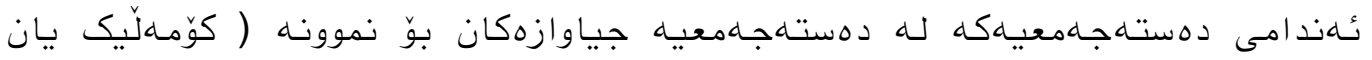

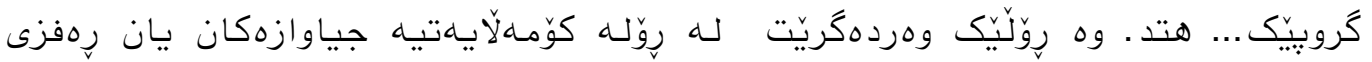

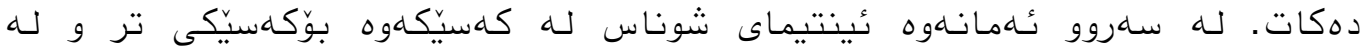

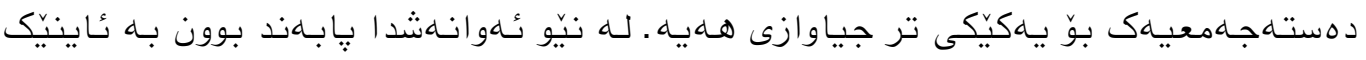

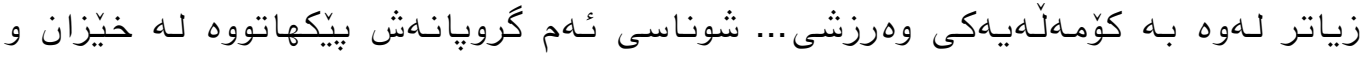

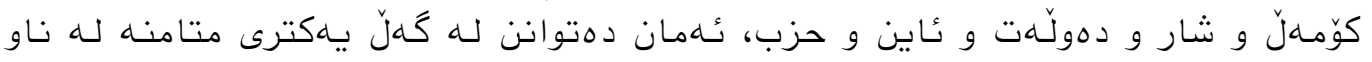

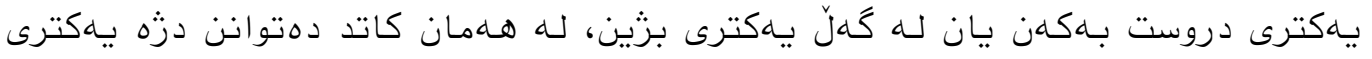

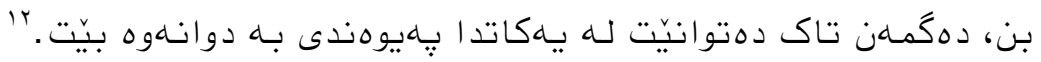

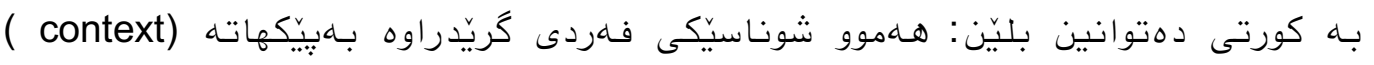

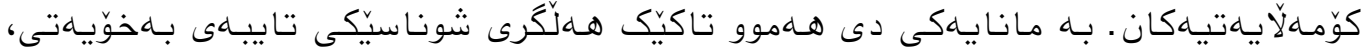

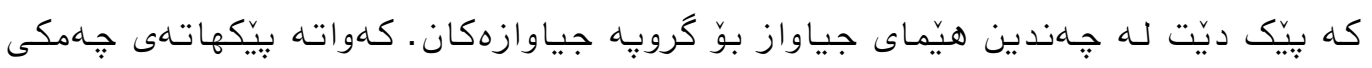

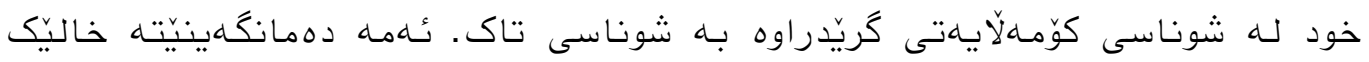

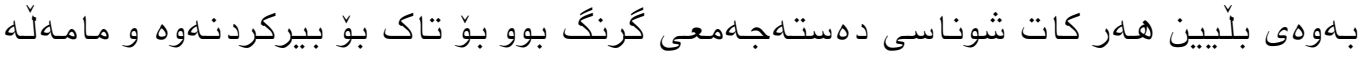

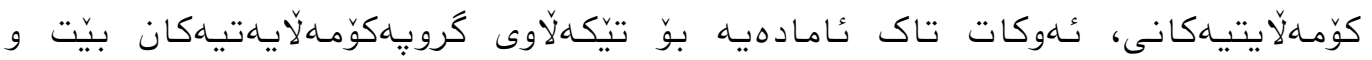

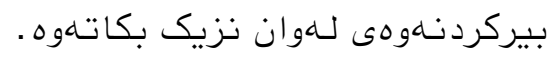

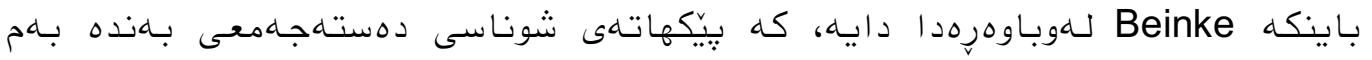

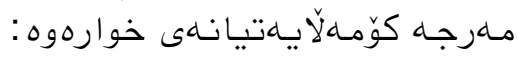

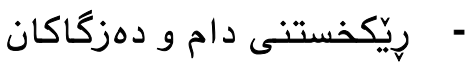

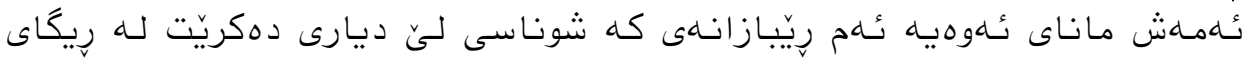

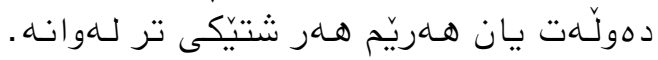

${ }^{12}$ Frank Marcinkowski, Barbara Pfetsch, Gerhard Vowe. Nationale Identitätals Medieninhalt: 2014 S. 22 Nomos Verlagsgesellschaft, Baden-Baden Germany. 


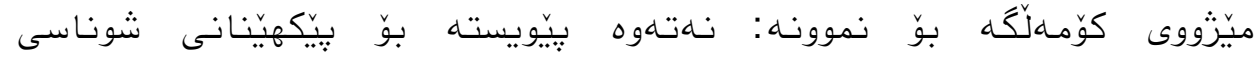

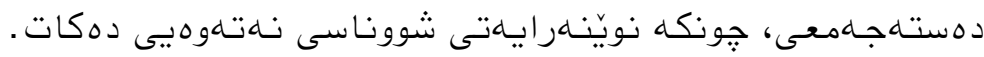

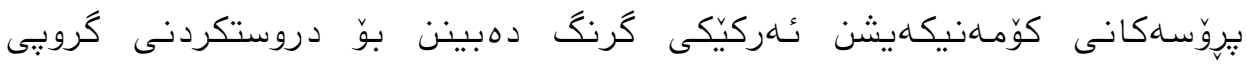

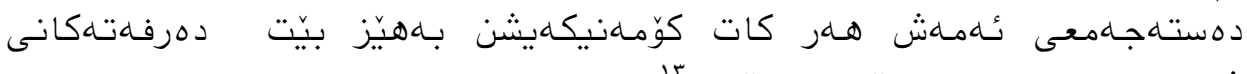

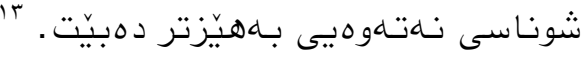

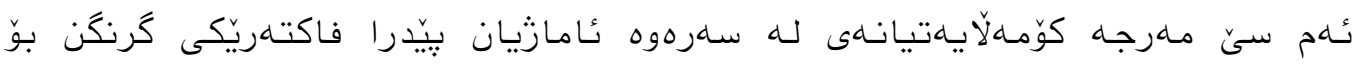

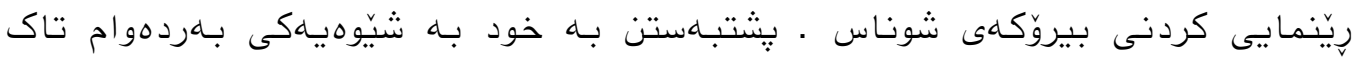

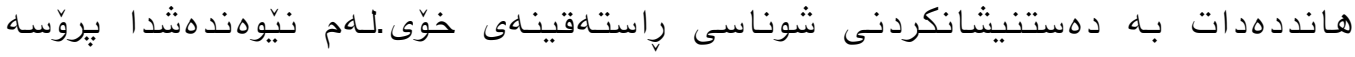

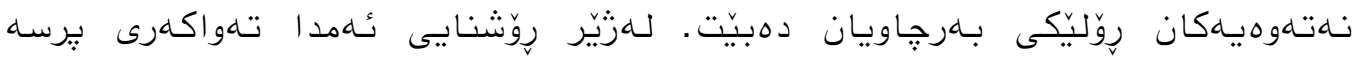

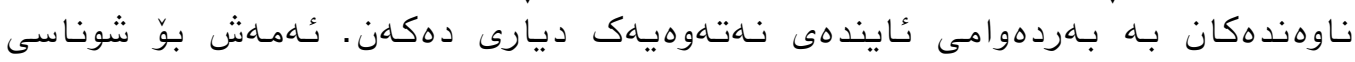

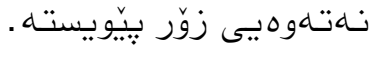

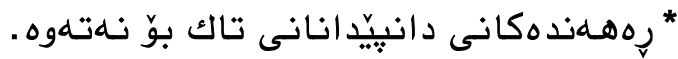

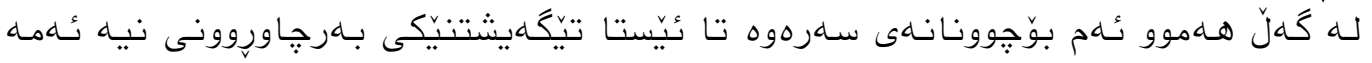

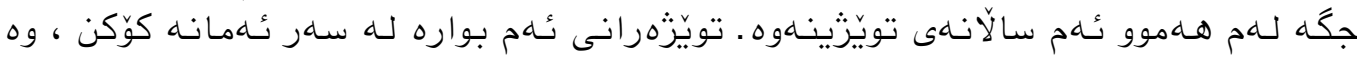

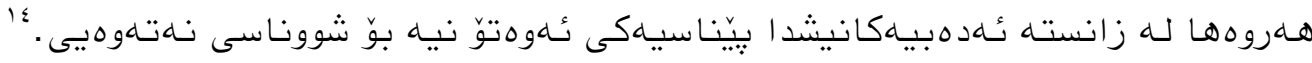

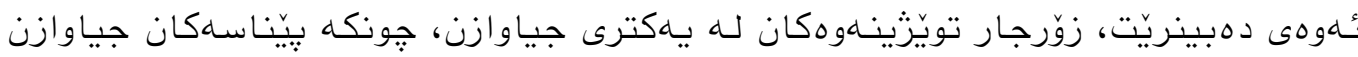

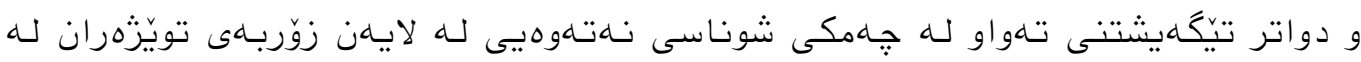

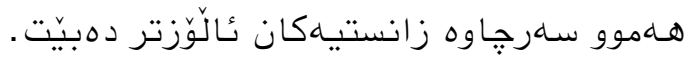

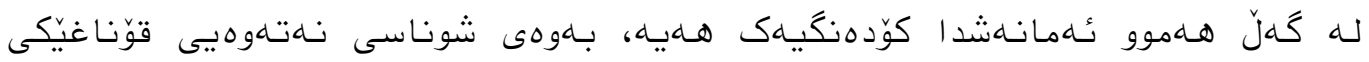

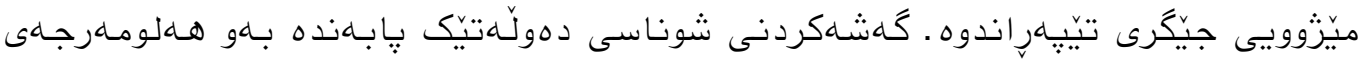

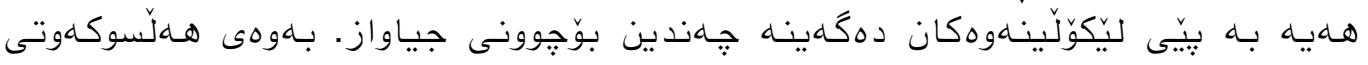

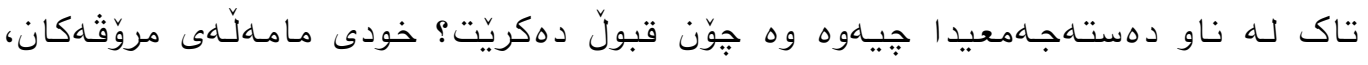

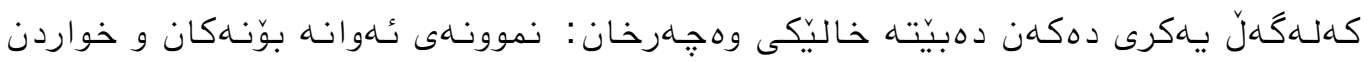

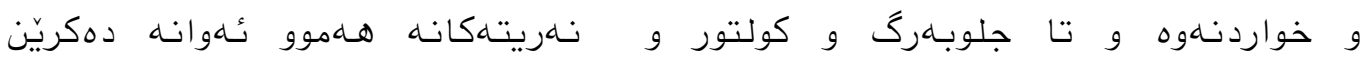

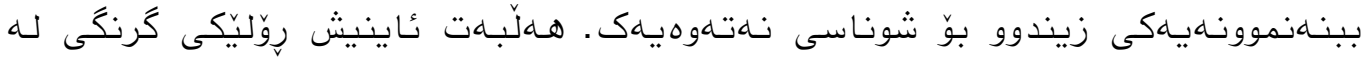

${ }^{13}$ Beinke, Inge: Identität - konstruktion und Soziale Tatsache. Ost - West. Europäischen Perspektive. 2008. S. 46

${ }^{14}$ Blank, T. (2002). S 93 Gemeinnutz oder Eigenwohl? Motive und Erscheinungsformen nationaler Identität im vereinigten Deutschland 1st ed. Mannheim: FRG. 


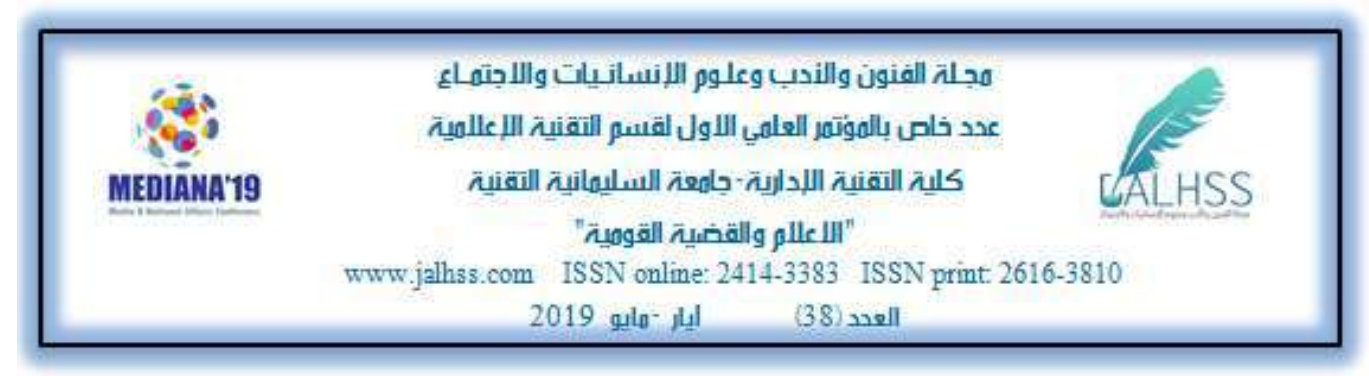

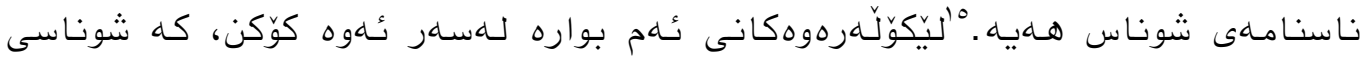

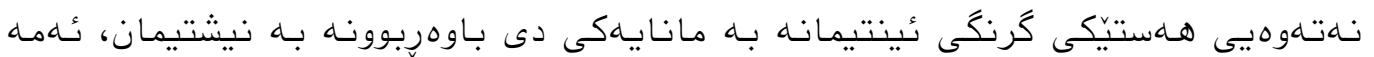

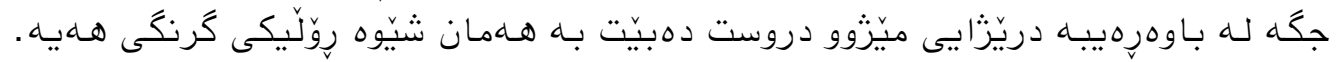

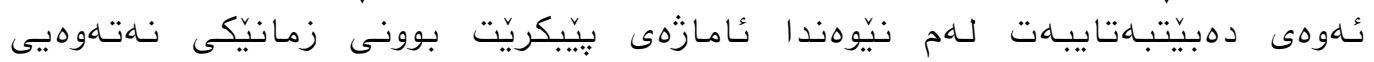

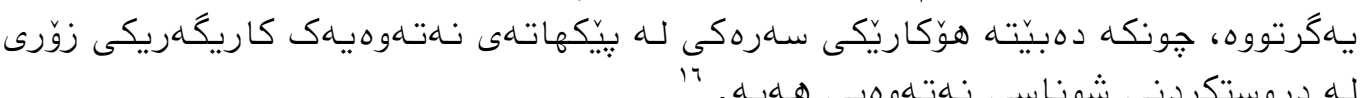

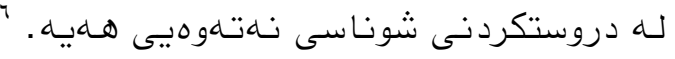

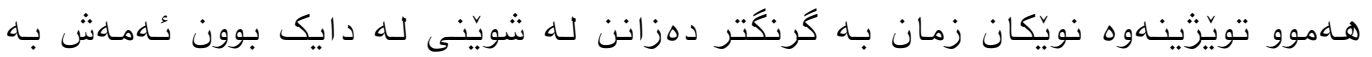

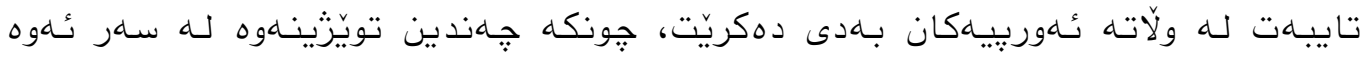

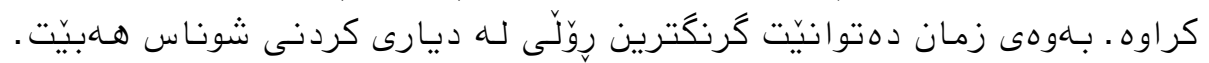

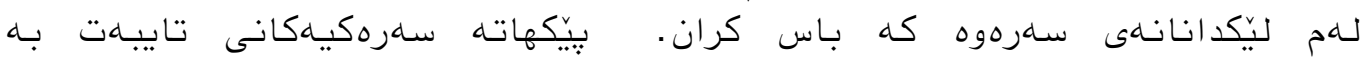

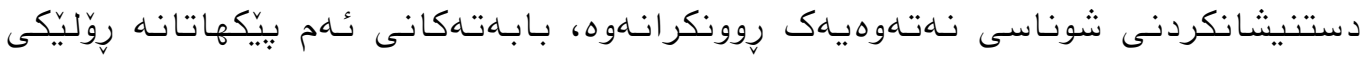

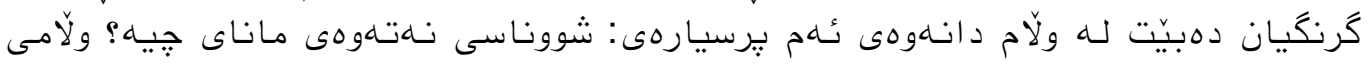

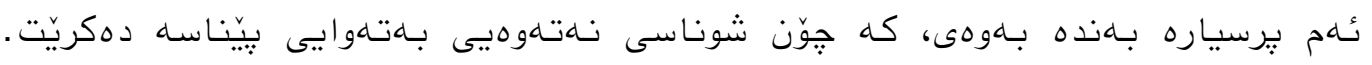

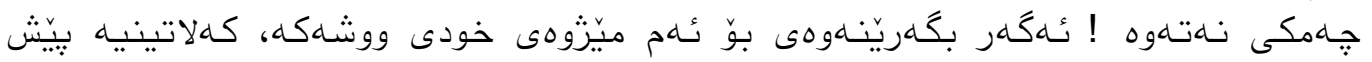

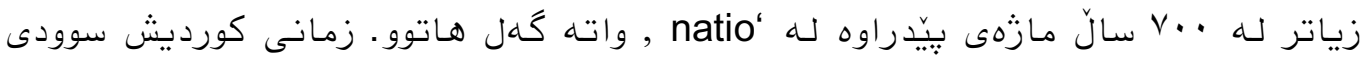

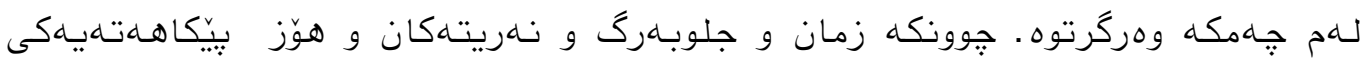

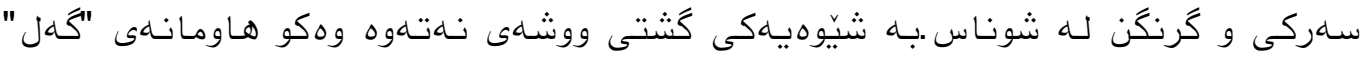

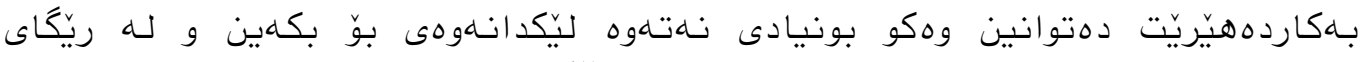

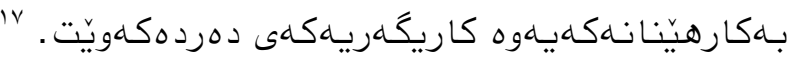

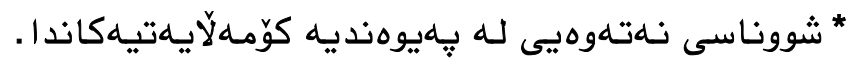

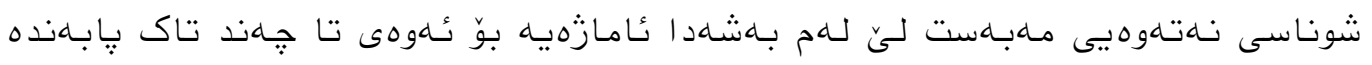

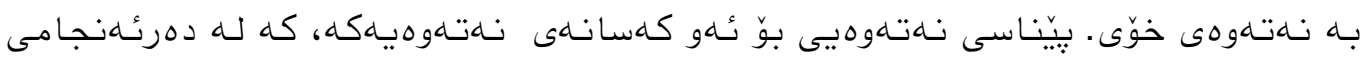

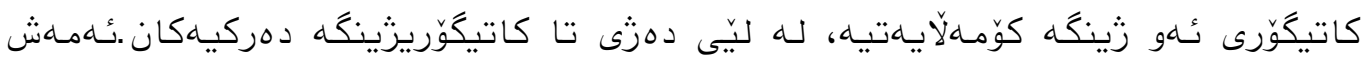

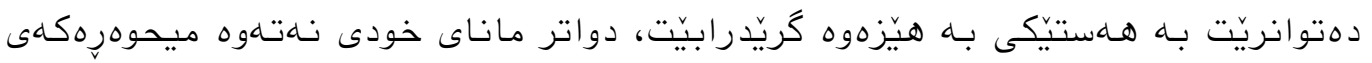

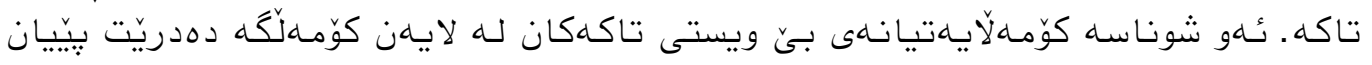

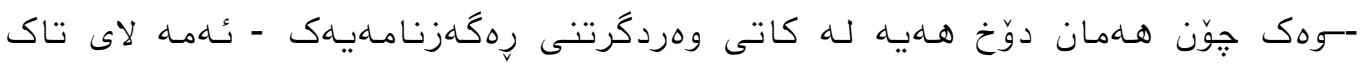

\footnotetext{
${ }^{15}$ Blank, T. (2002). S 96

${ }^{16}$ Depenheuer, O. (2006). „Nationale Identität und europäische Gemeinschaft. Grundbedingungen politischer Gemeinschaftsbildung."Nationale Identität im vereinten Europa. Hg. Günter Buchstab und Rudolf Uertz. Freiburg, Basel und Wien: Herder, 55-74.

${ }^{17}$ Depenhauer, 2006: S. 78
} 


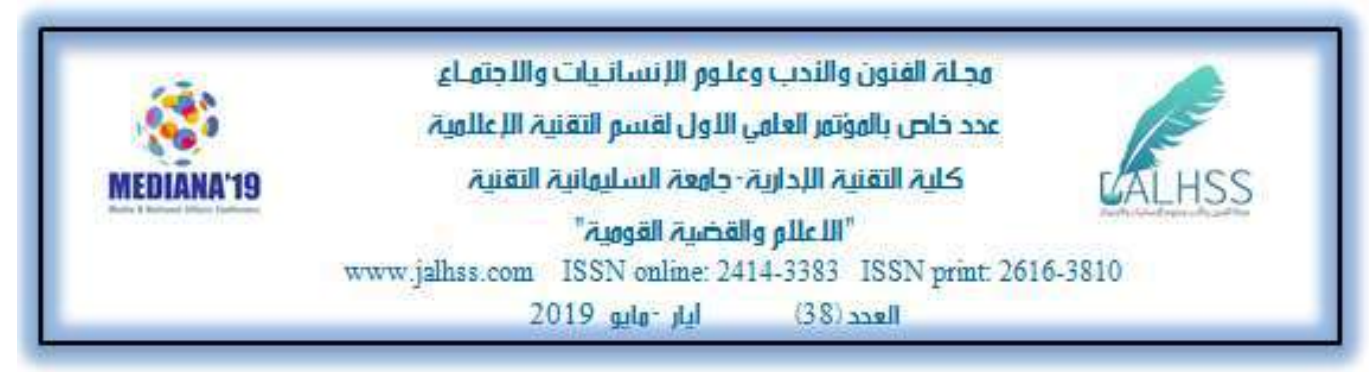

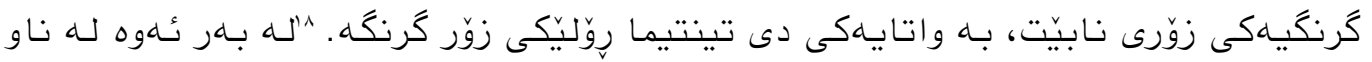

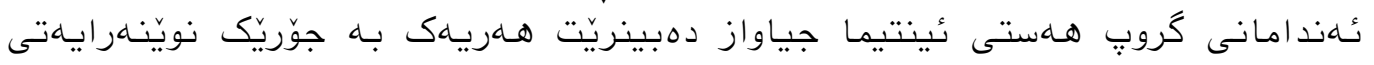

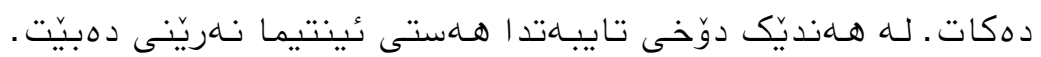
Tajfel

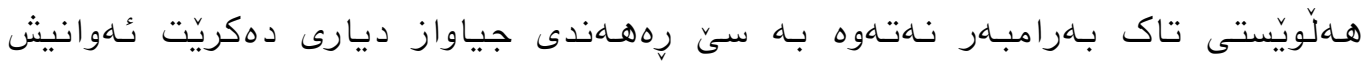

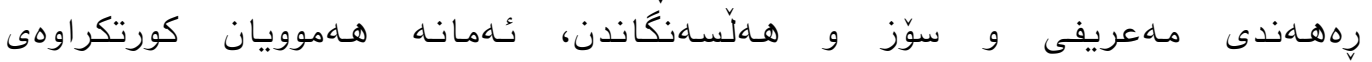

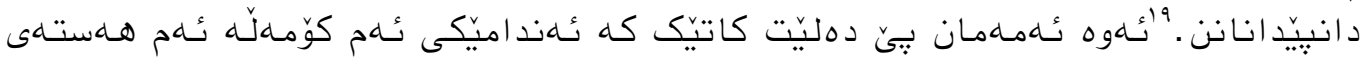

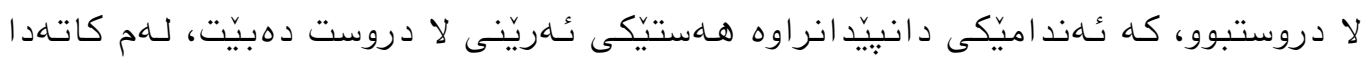

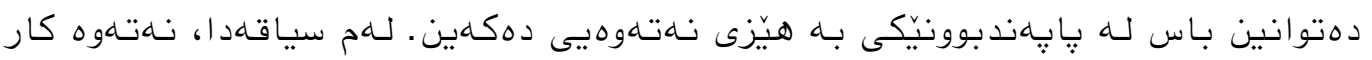

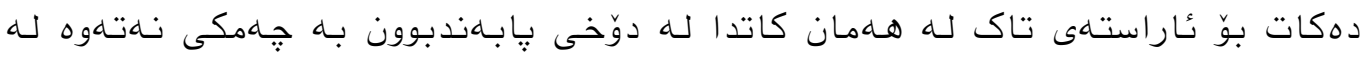

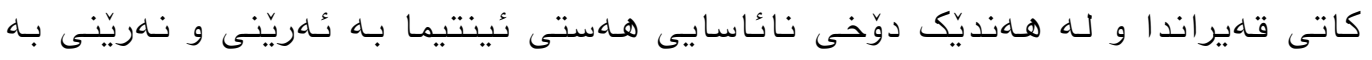

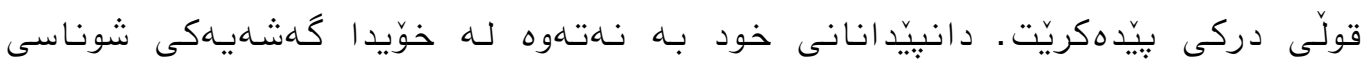

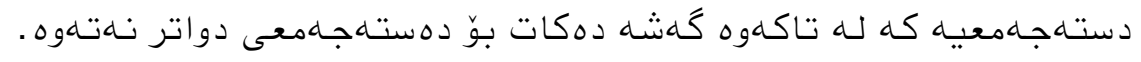

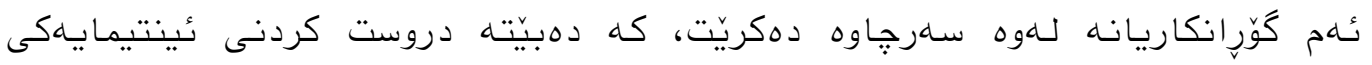

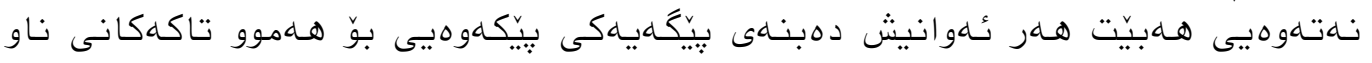

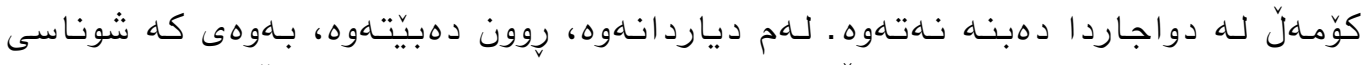

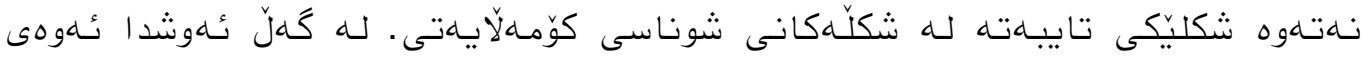

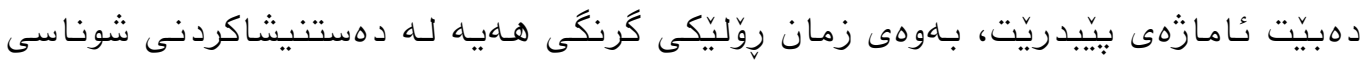

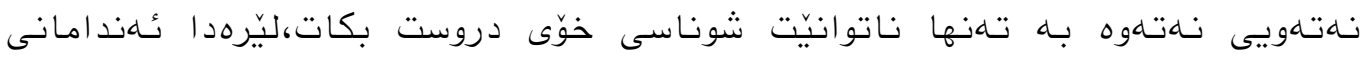

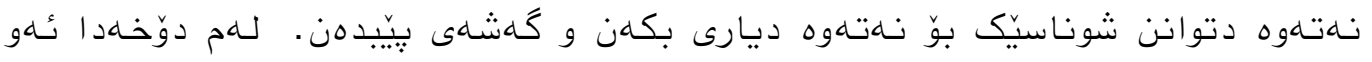

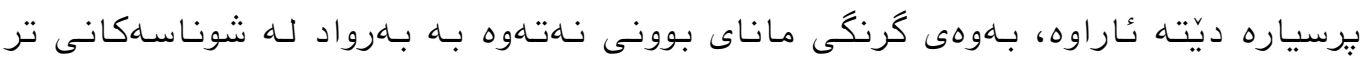

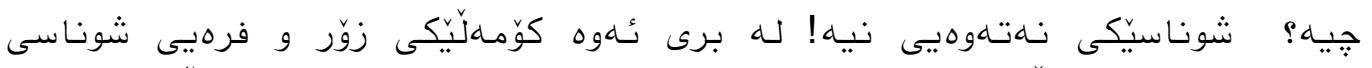

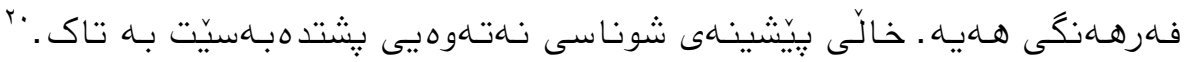

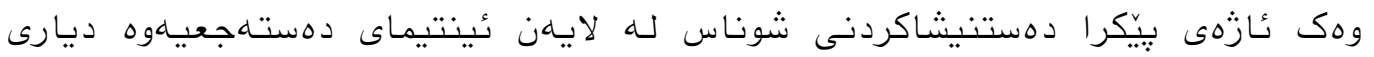

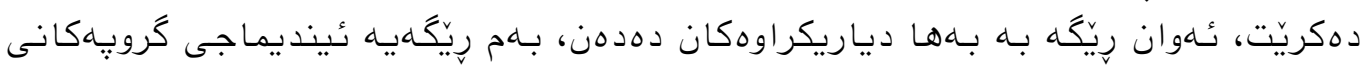

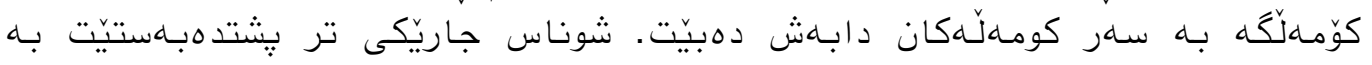

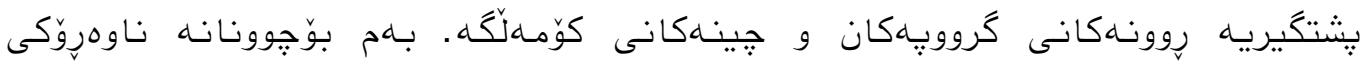

${ }^{18}$ Meulemann, H. (Ed.). (2013). Werte und nationale Identität im vereinten Deutschland: Erklärungsansätze der Umfrageforschung. Springer-Verlag.

${ }^{19} \mathrm{H}$. Tajfel, J. C. Turner: The social identity theory of intergroup behavior. In: S. Worchel, W. G. Austin (Hrsg.): Psychology of intergroup relations. Nelson-Hall, Chicago, IL 1986, S. 7-24.

${ }^{20} \mathrm{H}$. Tajfel, J. C. Turner... S 28-30 


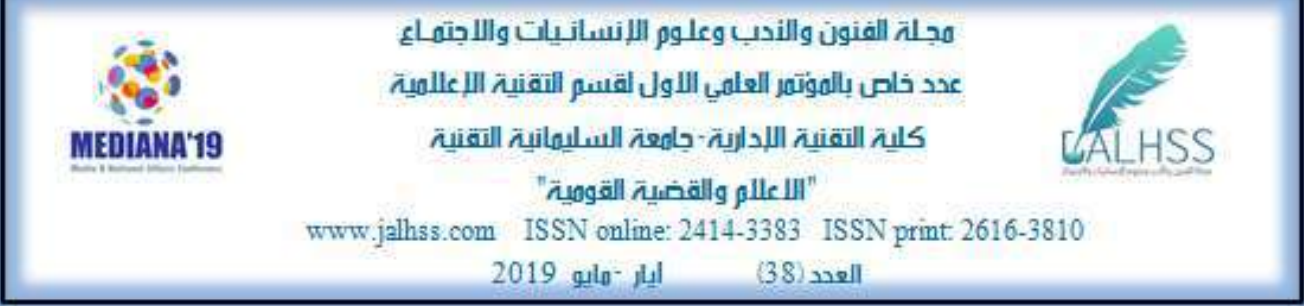

شوناسى نـهتهوهيى لـه لايسهن خودى تاكهكان تردا ديارى دهكريّن بـهوهى، كه ئهندامن لـه

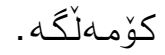

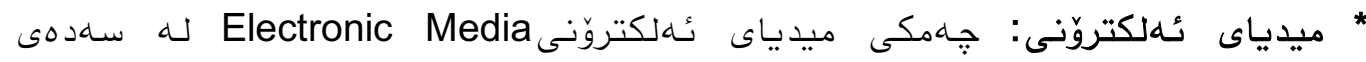

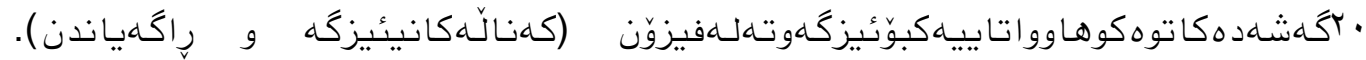

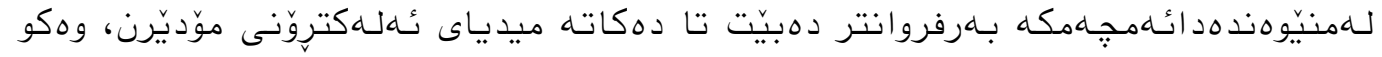

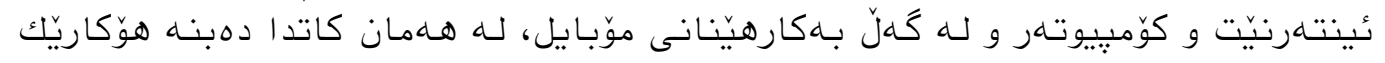

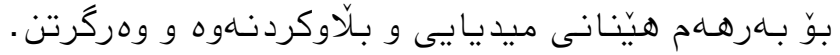

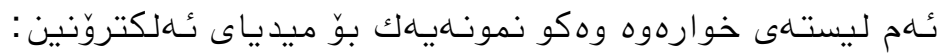

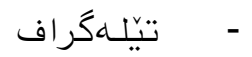
-

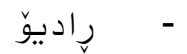
CD -

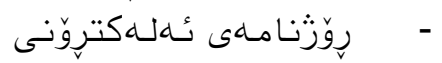
-

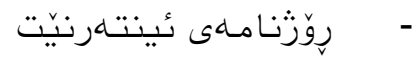

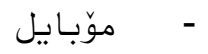

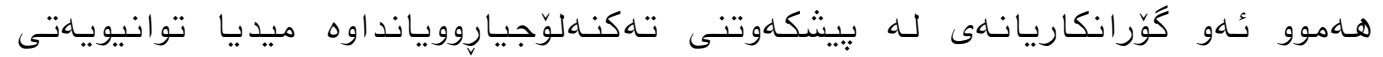

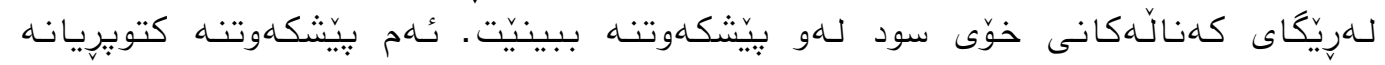

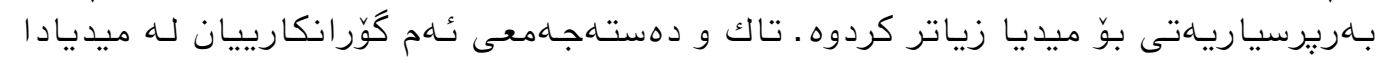

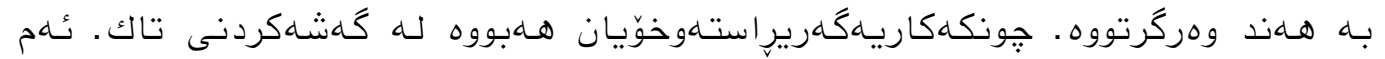

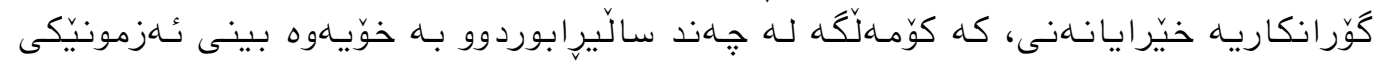

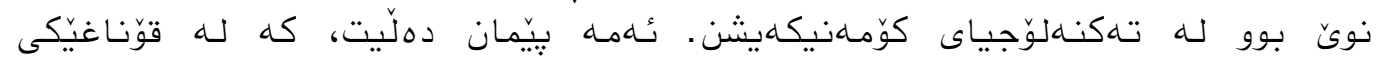

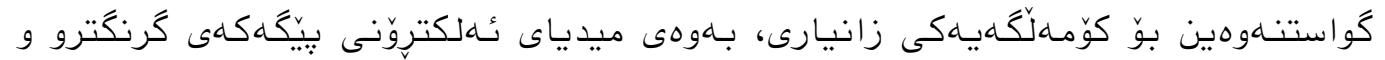

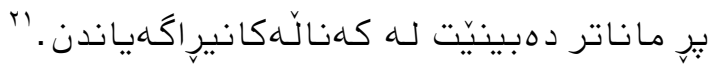

${ }^{21} \mathrm{https} / / /$ www.credia.de/e-magazin/. 17.03.17

306

DOI: $10.33193 /$ JALHSS.38.12 


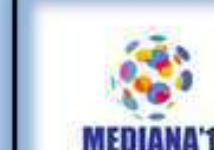

MEDIĀMA'19
هجلم الفنون والندب وعلوم اللإنسانيات واللاجتهـاع

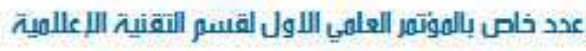

كلية التقنية اللدازية -جاهعت السليهانية التهنيت

"

www.jalhss.com ISSN online: 2414-3383 ISSN print $2616-3810$

2019 glo الع

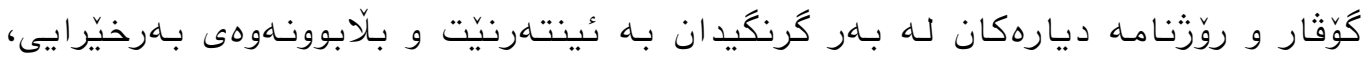

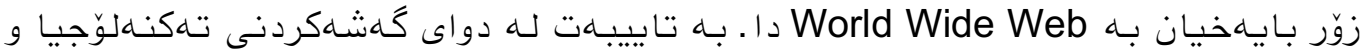

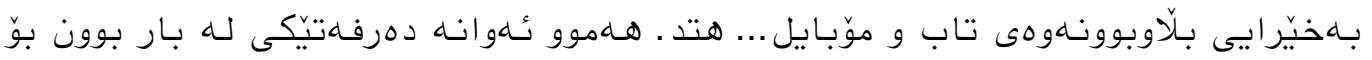

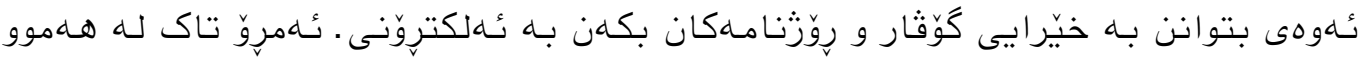

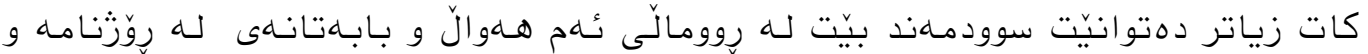

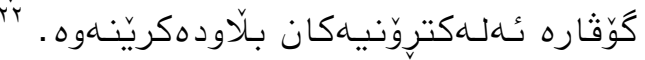

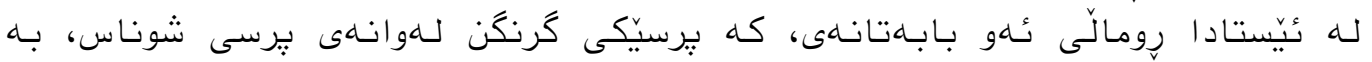

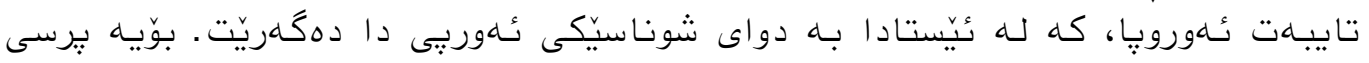

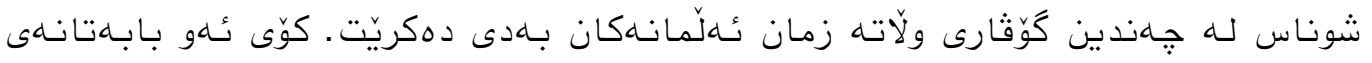

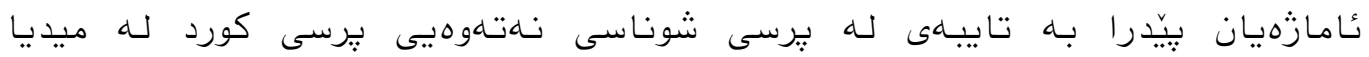

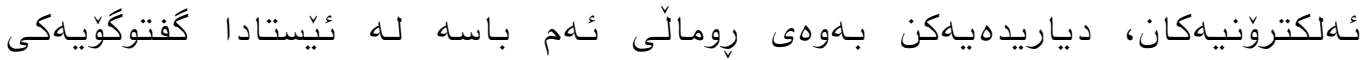

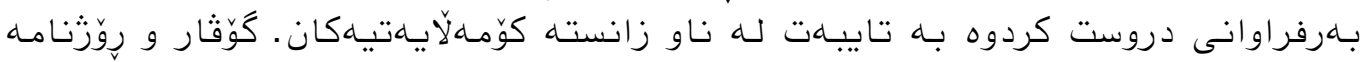

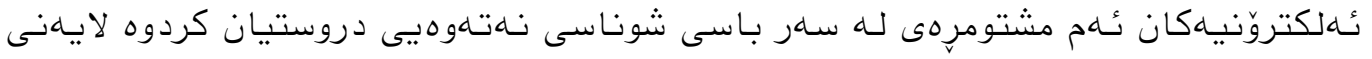

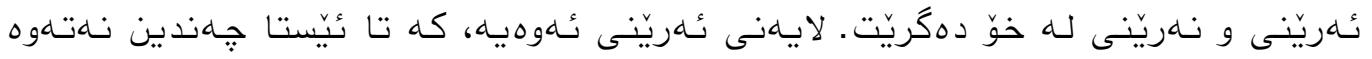

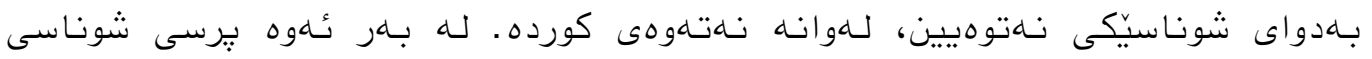

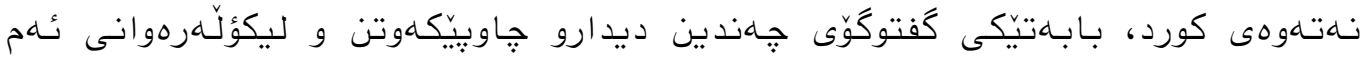

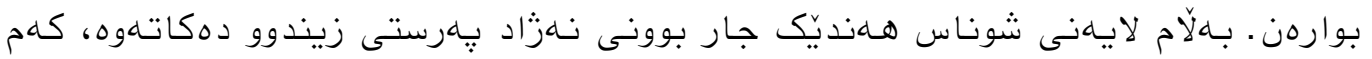

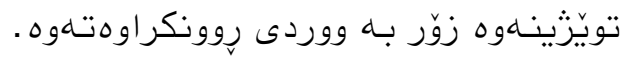

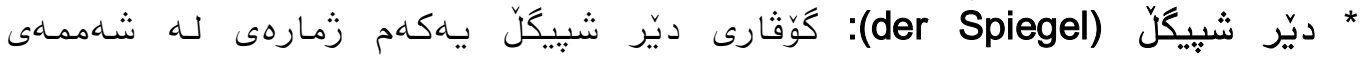

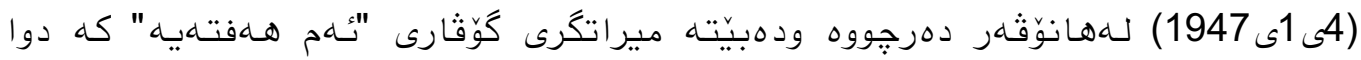

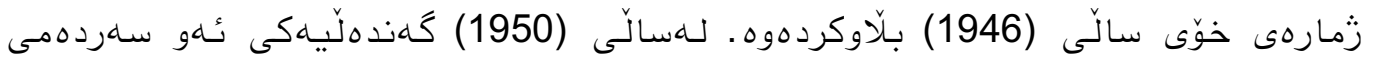

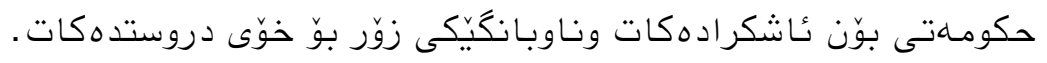

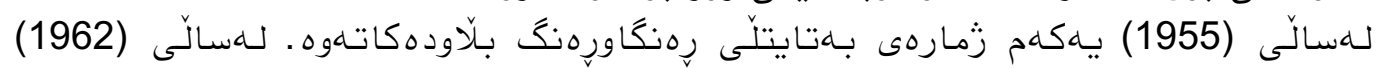

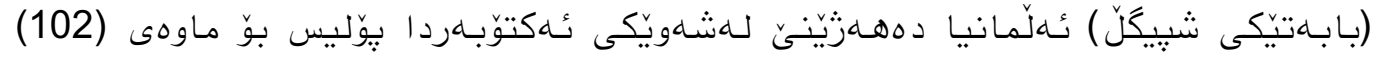

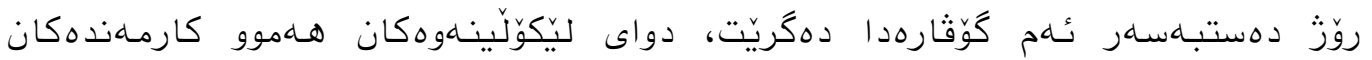

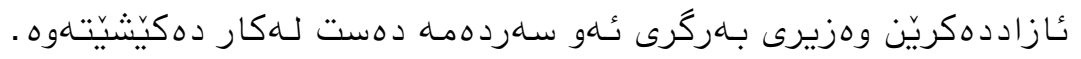

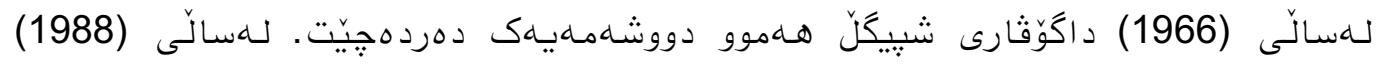

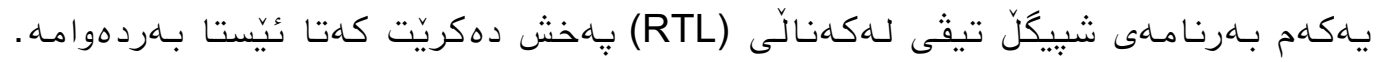

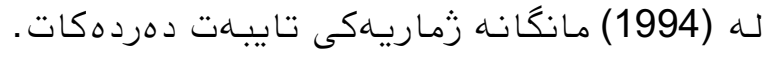

${ }^{22}$ https://www.credia.de/e-magazin/ 12.04.2019 


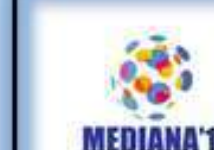

MEDIลิMA'19
هجِلة الفنون والندب وعلوم اللإنسانيات واللاجِماعِ

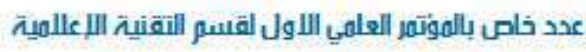

كلية التقنية اللدازية - جاهعت السليهانية التهنيت

"

www.jalhss.com ISSN online: $2414-3383$ ISSN print $2616-3810$

2019 gll

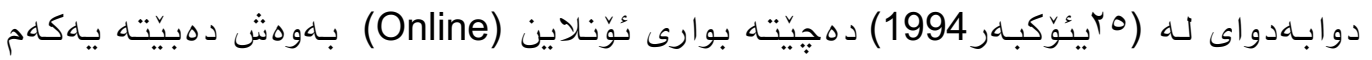

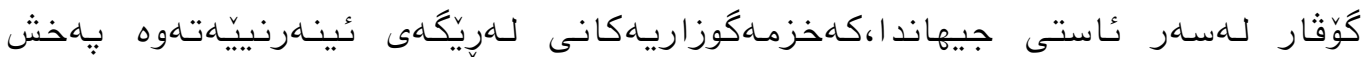

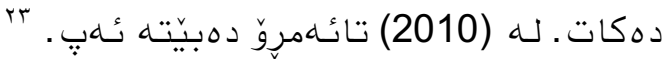

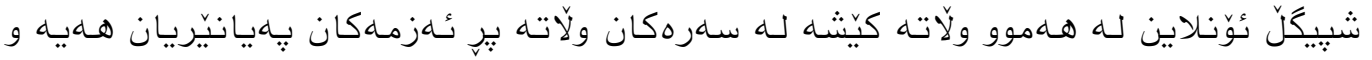

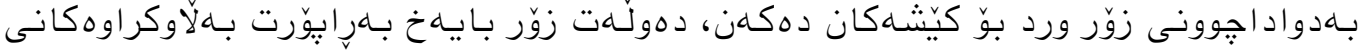

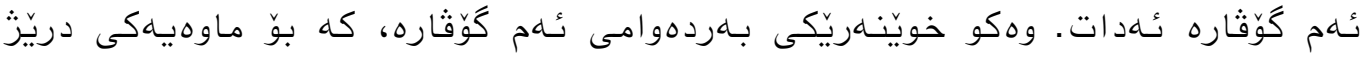

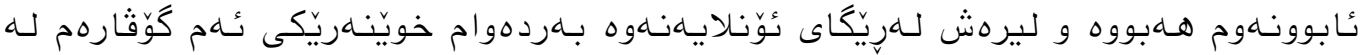

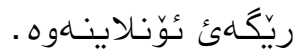

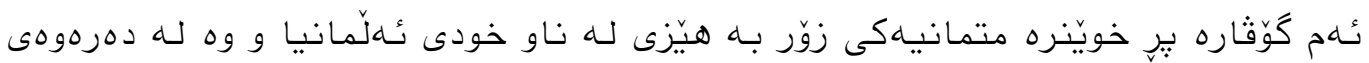

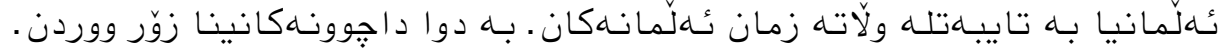

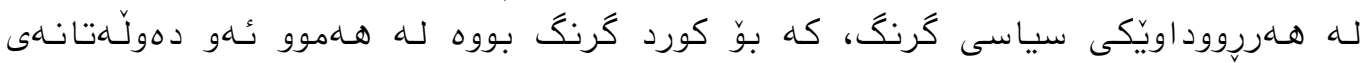

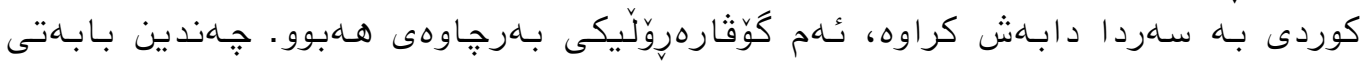

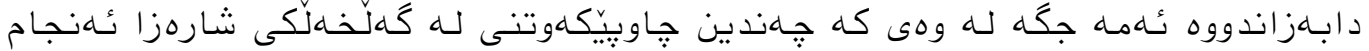

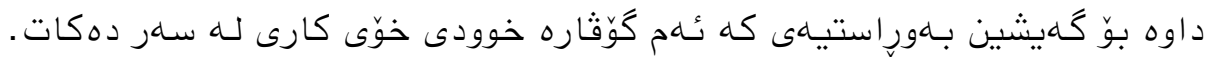

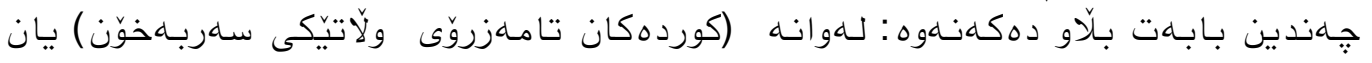

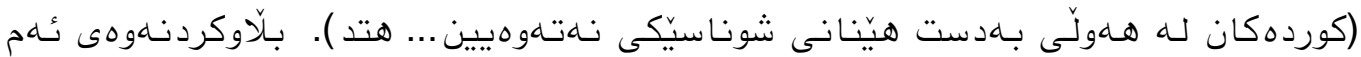

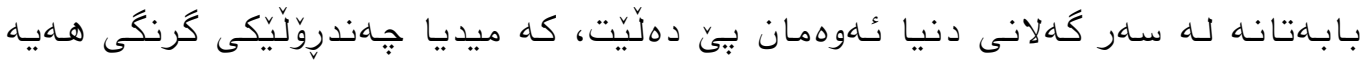

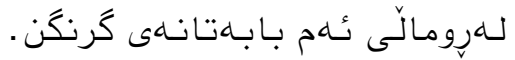

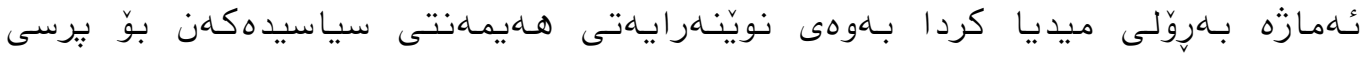

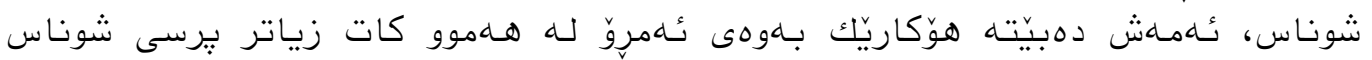

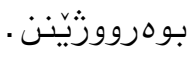

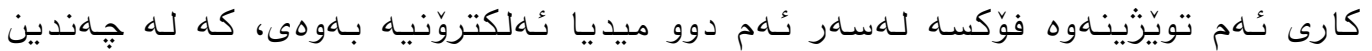

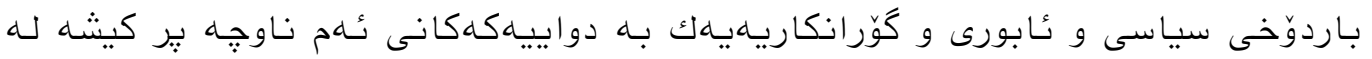

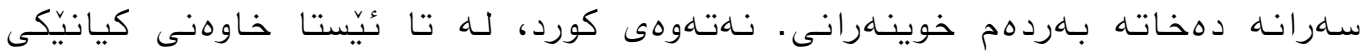

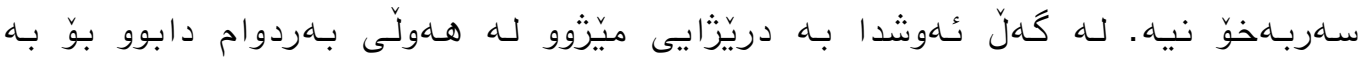

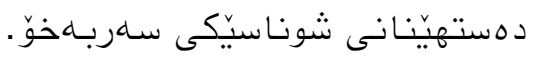

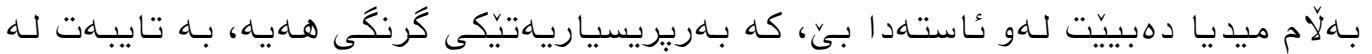

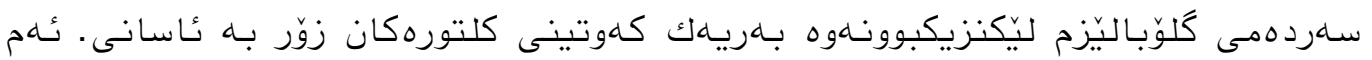

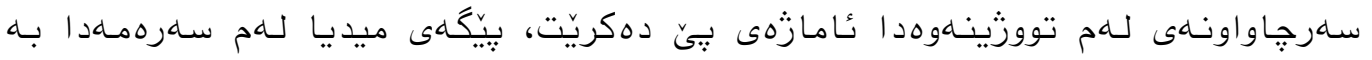

${ }^{23} \mathrm{http}$ ://www.spiegelgruppe.de/spiegelgruppe/home.nsf/Navigation/6CE8D16B87C4BD0AC1256F5F0 0350C5A?OpenDocument 22.03.19

308

DOI: $10.33193 /$ JALHSS.38.12 


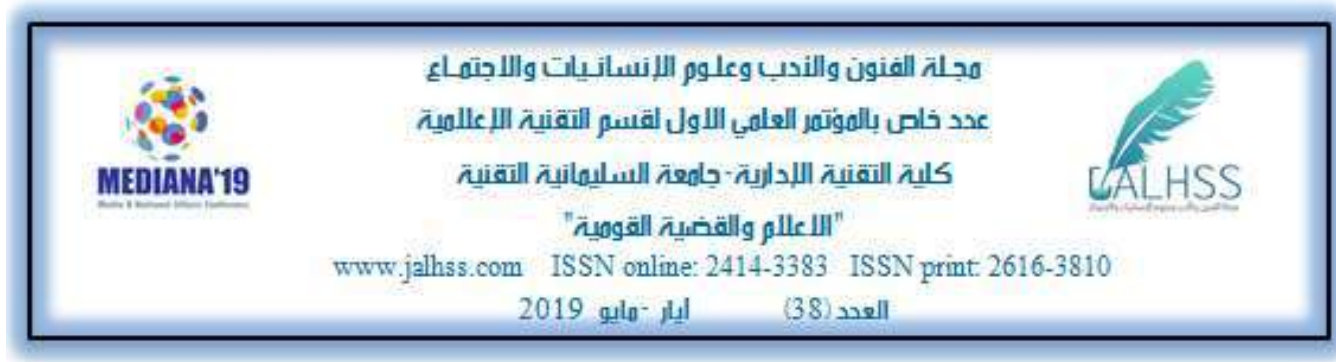

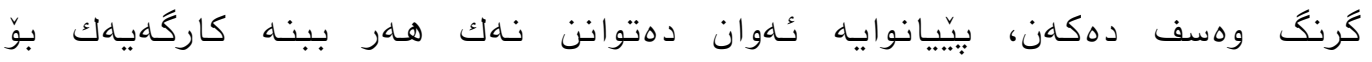

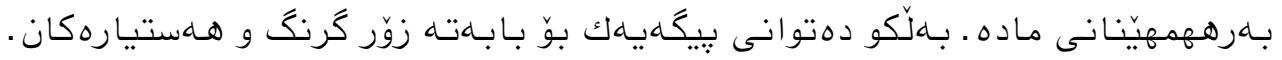

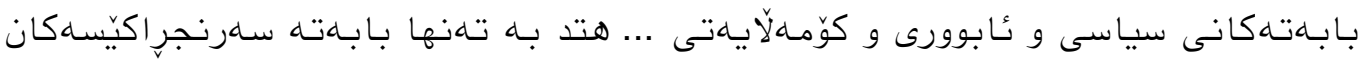

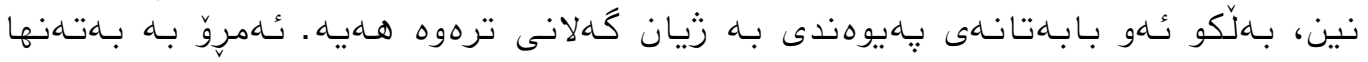

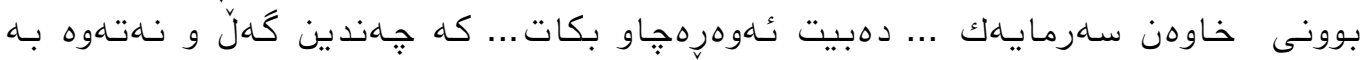

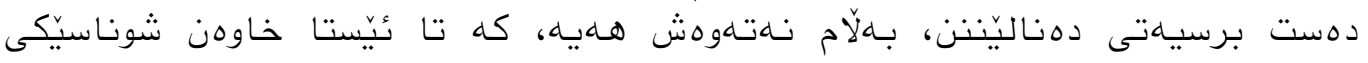

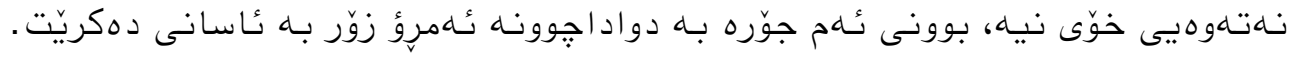

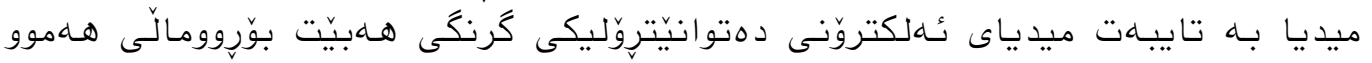

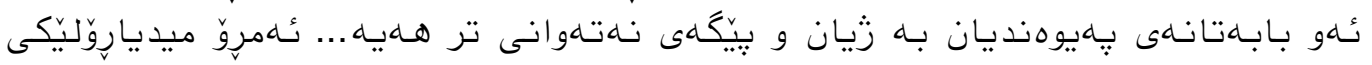

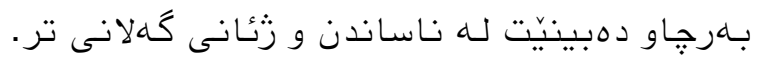

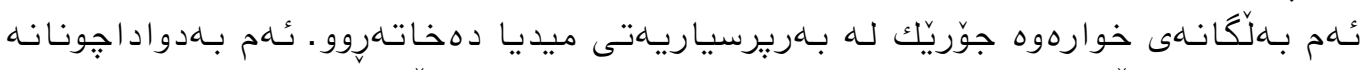

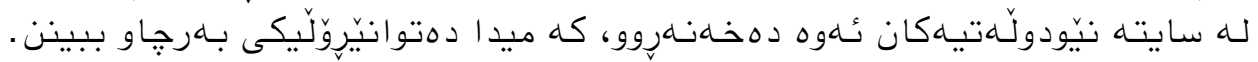

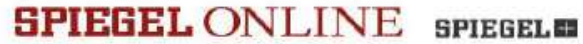

\section{Q Arrektion}

\footnotetext{
$\equiv$ Mena | Polltk Meinung Wirtschaft Panorama Sport Kultur Netzwelt Wissenschaft mehr V POLITIK

Schlagzeilen | DAX 11428,78 | Abo
}

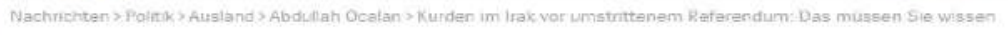

\section{Kurden im Irak}

\section{Sehnsucht nach dem eigenen Staat}

Iraks Kurden wollen über ihre Unabhängigkeit abstimmen. Sie stoß̉en aut massiven Widerstand: Irak, Iran, Türkei und die USA sind dagegen, selbst die Uno warnt - nur Israel ist dafür. Die Hintergründe.

Von hasnain Kazim $\smile$, Dominik Peters $\backsim$ und Christoph Sydow $\checkmark$

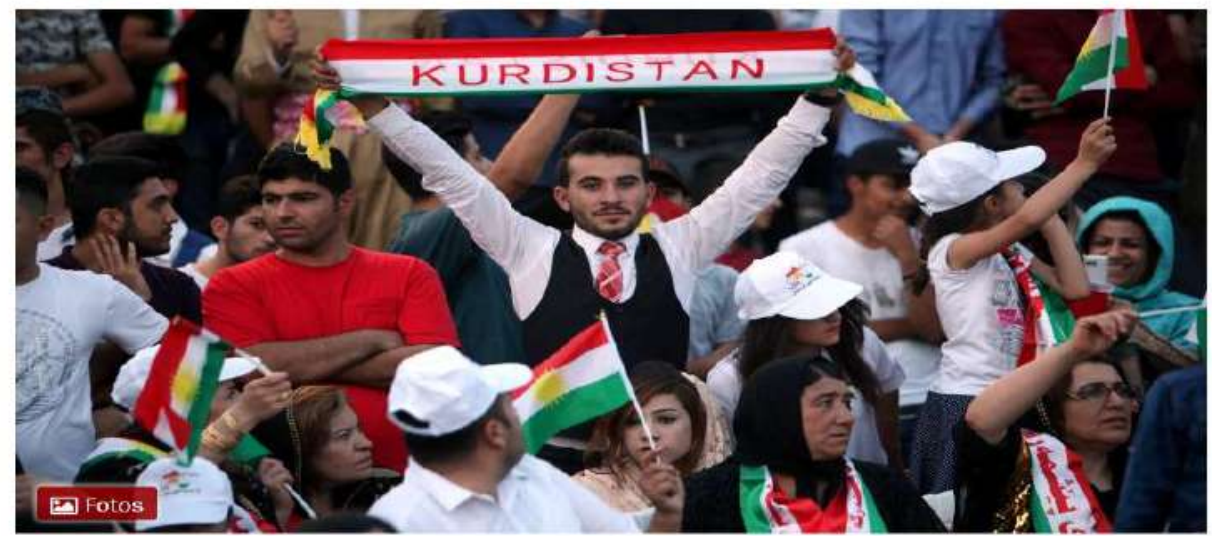




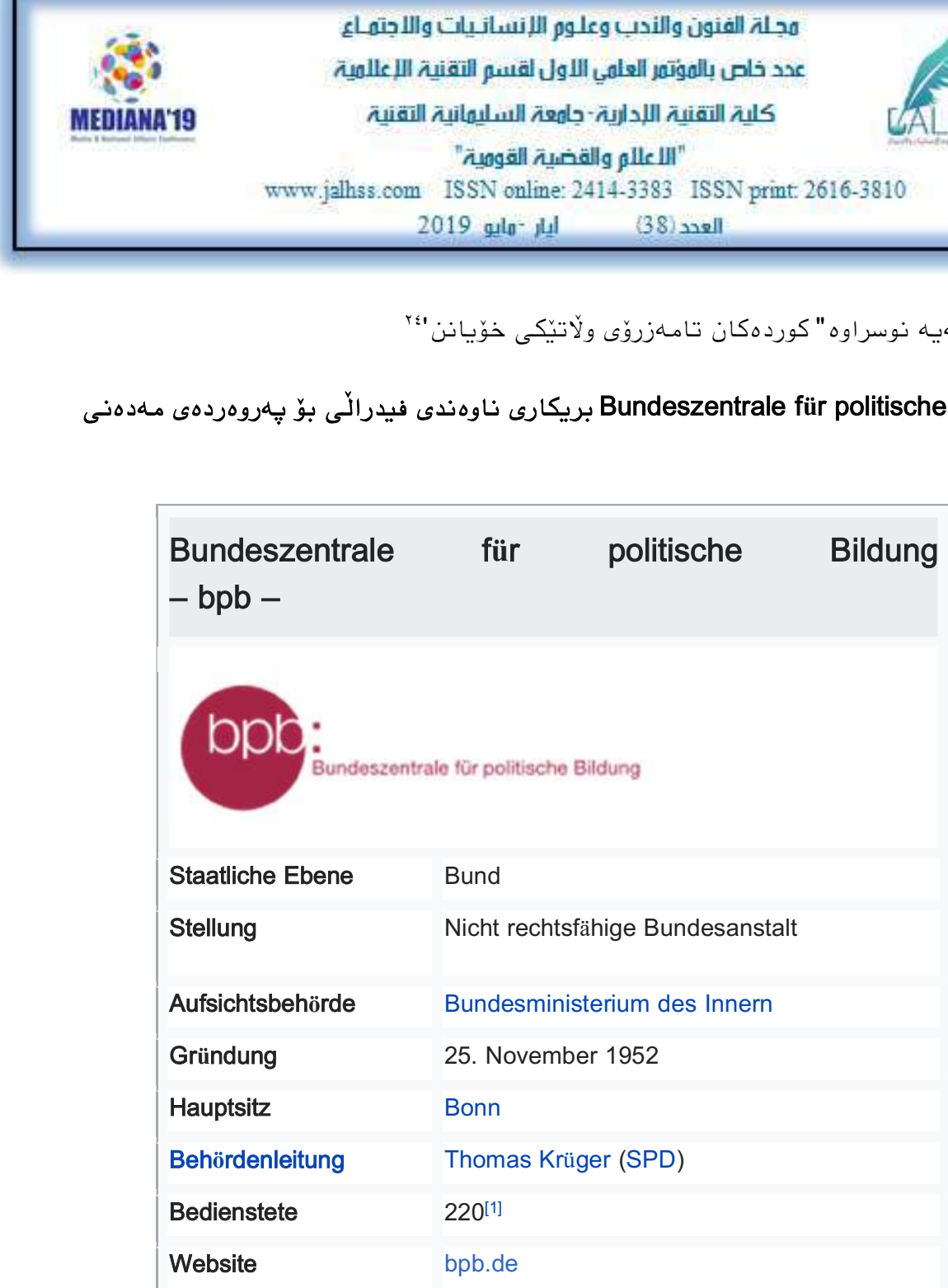

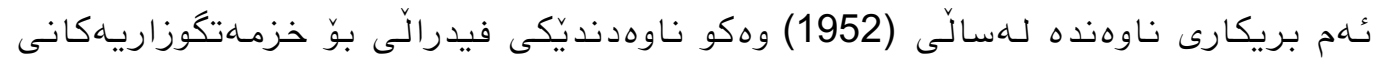

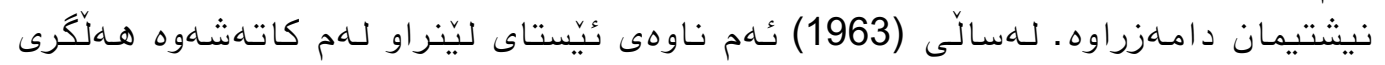

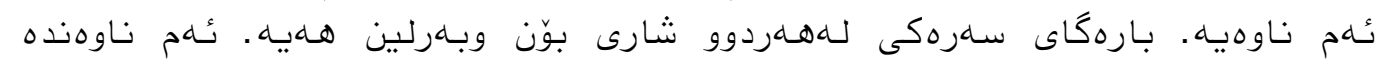

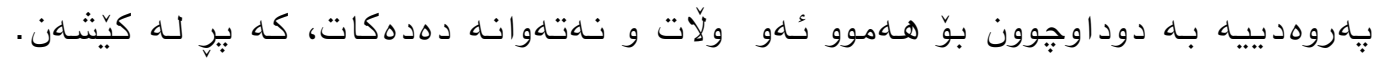

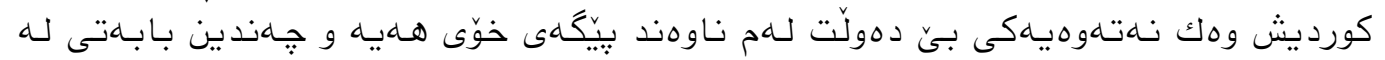

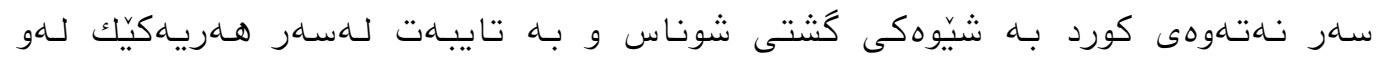

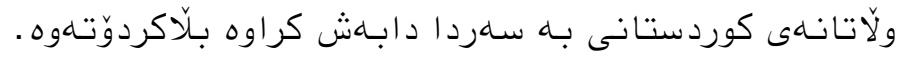

${ }^{24}$ https://www.spiegel.de/suche/?suchbegriff=Kurden\&suchzeitraum 20.02.2019 


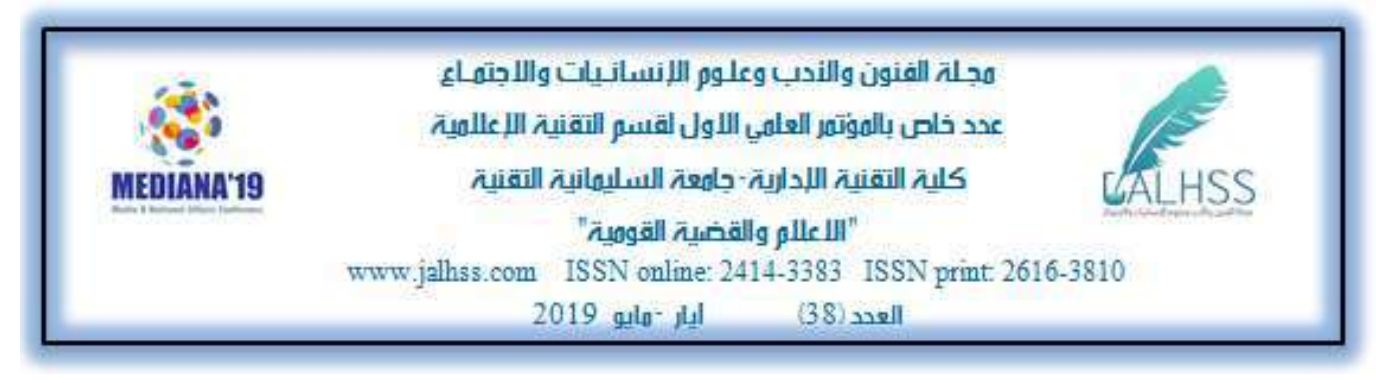

بهدواد اجوونهاكانى لـهسهر برسى كورد زوّر وردهو لـه لايهن كهانسانى شارهزا و بـه تايبهات

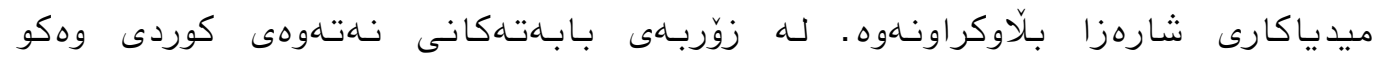

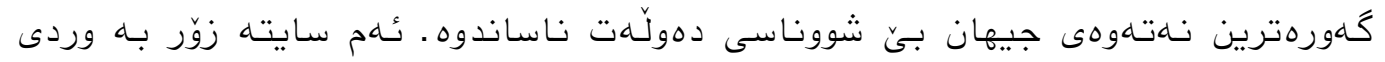

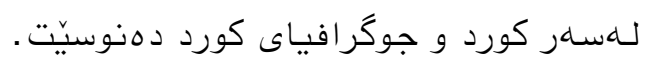

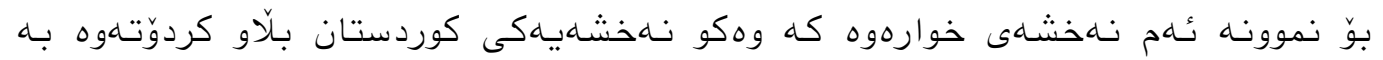

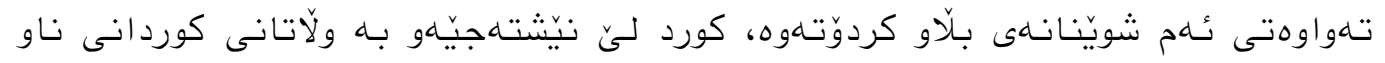

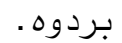

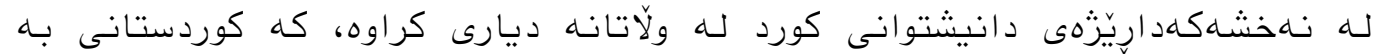

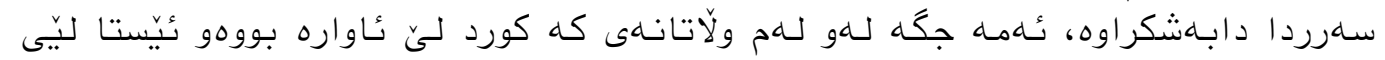

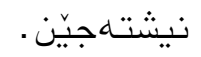

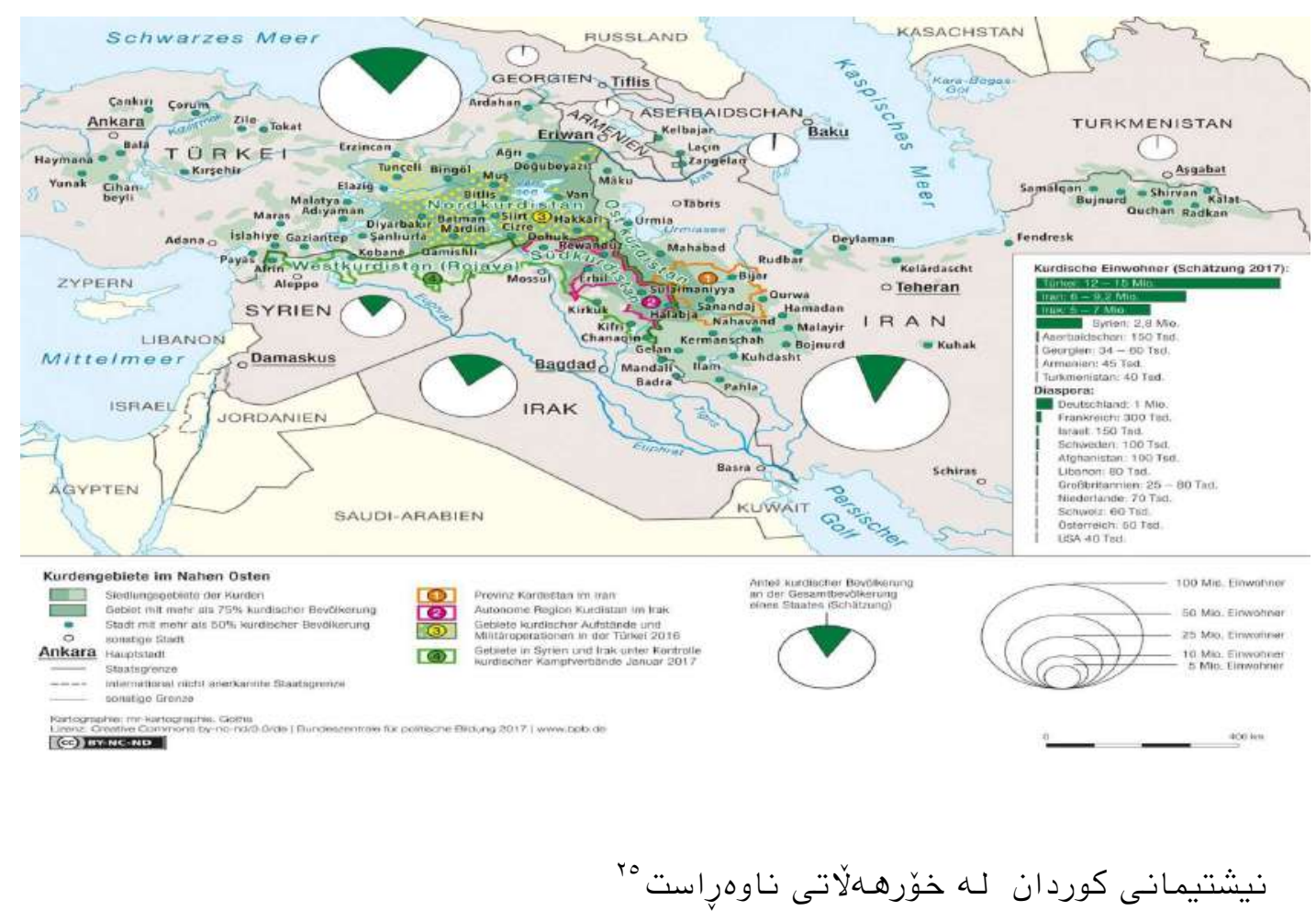

${ }^{25} \mathrm{https}: / / \mathrm{www} \cdot \mathrm{bpb} . \mathrm{de} /$ internationales/weltweit/innerstaatlichekonflikte/54641/kurdenkonflikt15.01.2019 


\section{\%क:}

MEDIĀMA'19
هجِلة الفنون والندب وعلوم اللإنسانيات واللاجتهـاع

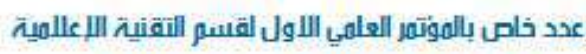
كلية التقنية اللدازية جاهعت السليهانية التقنيت

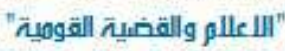

www.jalhss.com ISSN online: 2414-3383 ISSN print $2616-3810$

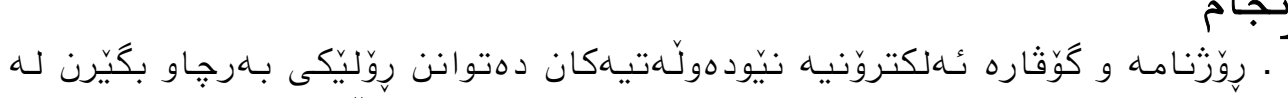

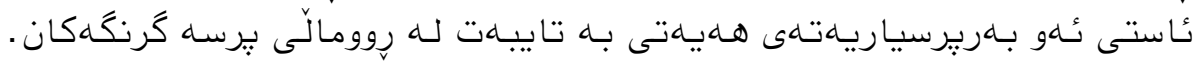

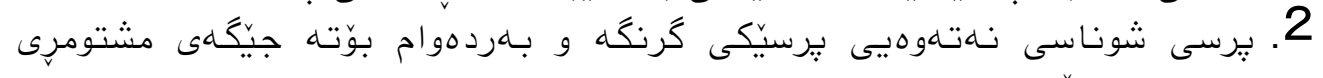

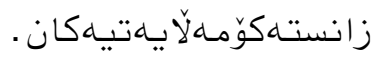

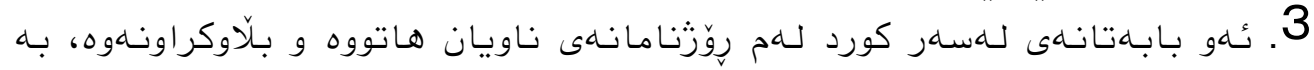

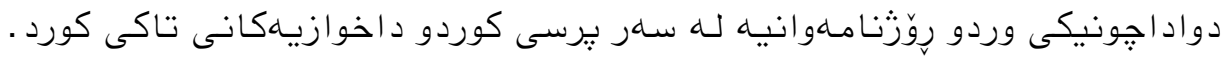

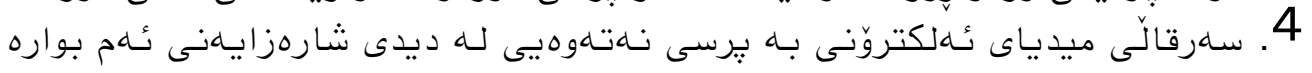

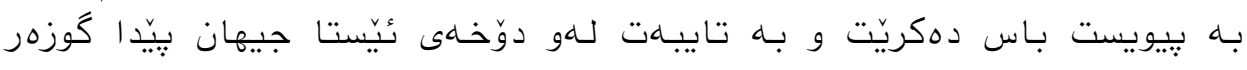

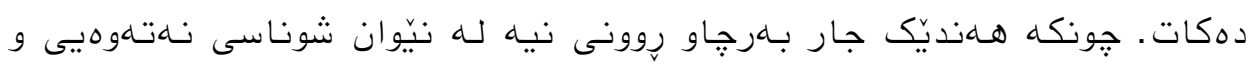

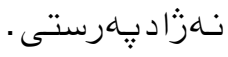

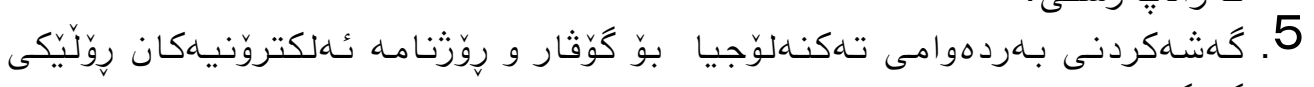

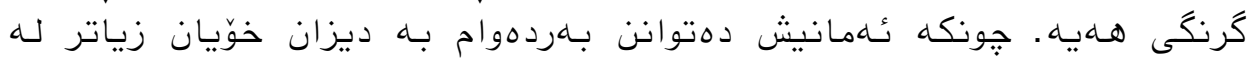

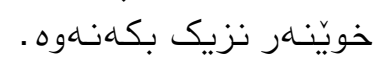

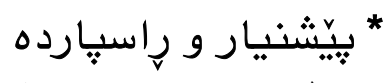

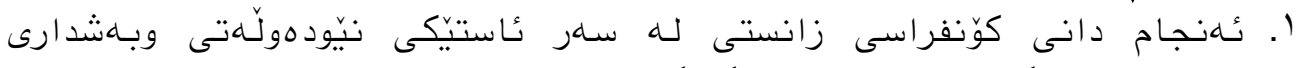

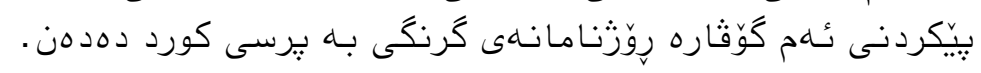

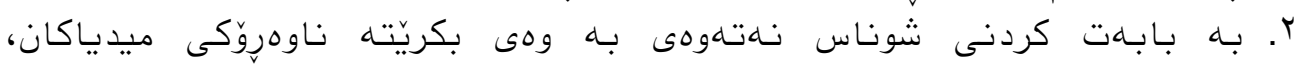

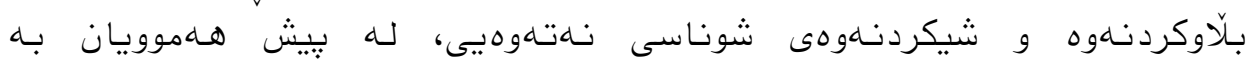

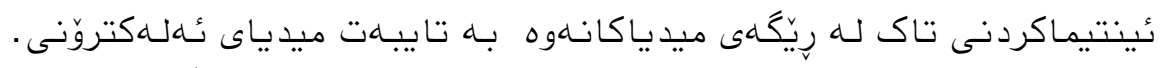

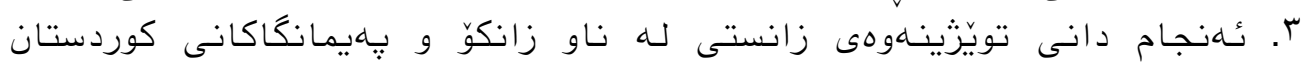

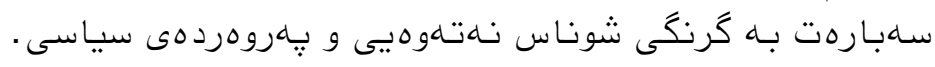


هج لات الفنون والندب وعاوم اللإنسانيات واللاجتهاع

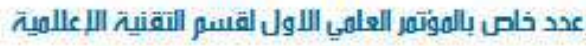

كلية التقنية اللدازية -جاهعت السليهانية التهنيت

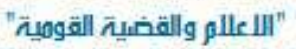

www jalhss.com ISSN online: 2414-3383 ISSN print 2616-3810

2019 gll

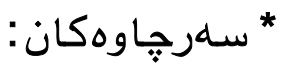

1. Sander Cvetkovic Sprachpolitik und nationale Identität im Sozialistischen Jugoslawien 2011 S. 28 - Instituts an der Freien Universität Berlin

2. Blank, T. (2002). S 93 Gemeinnutz oder Eigenwohl? Motive und Erscheinungsformen nationaler Identität im vereinigten Deutschland 1st ed. Mannheim: FRG.

3. Depenheuer, O. (2006). „Nationale Identität und europäische Gemeinschaft. Grundbedingungen politischer Gemeinschaftsbildung."Nationale Identität im vereinten Europa. Hg. Günter Buchstab und Rudolf Uertz. Freiburg, Basel und Wien: Herder, 55-74.

4. C. Leggewie u.a.: Der Kampf um die europäische Erinnerung - München 2011: C.H. Beck Verlag

5. Atteslander Peter, Methoden der empirischen Sozialforschung, Berlin, New York: Walter de Cruyter GmbH 10. neu überarbeitete und erweiterte Auflage 2003.

6. Meier Klaus, Journalistik, Konstanz: UVK Verlagsgesellschaft, 2007.

7. Norbert Ricken: Anerkennung als pädagogisches Problem. Markierungen im erziehungswissenschaftlichen Diskurs. 2010. Universität Buchum

8. Tenorth / Tippelt (Hrsg.) Lexikon Pädagogik 2007

9. Frank Marcinkowski, Barbara Pfetsch, Gerhard Vowe. Nationale Identitätals Medieninhalt: 2014 Nomos Verlagsgesellschaft, Baden-Baden Germany.

10. Beinke, Inge: Identität - konstruktion und Soziale Tatsache. Ost - West. Europäischen Perspektive. 2008.

11. Liebert, W.-A. (2003). $\mathrm{Zu}$ einem dynamischen Konzept von Schlüsselwörtern. Zeitschrift für angewandte Linguistik,

12. H. Tajfel, J. C. Turner: The social identity theory of intergroup behavior. In: S. Worchel, W. G. Austin (Hrsg.): Psychology of intergroup relations. NelsonHall, Chicago, IL 1986,

13. Meulemann, H. (Ed.). (2013). Werte und nationale Identität im vereinten Deutschland: Erklärungsansätze der Umfrageforschung. Springer-Verlag.

$$
\text { سارجهاوهكان نيُينتسرنيّت }
$$

14. https://www.spiegel.de/suche/?suchbegriff=Kurden\&suchzeitraum

15. https://www.owep.de/artikel/634/identitaet-konstruktion-und-soziale-tatsache.

16. https://www.bpb.de/internationales/weltweit/innerstaatlichekonflikte/54641/kurdenkonflikt.

17. https://www.credia.de/e-magazin/ 